\title{
(Allenylidene)ruthenium Complexes with Redox-Active Substituents and Ligands
}

\author{
Stephan Hartmann, ${ }^{[a]}$ Rainer F. Winter, ${ }^{*[a]}$ Birgit M. Brunner, ${ }^{\text {[a] }}$ Biprajit Sarkar, ${ }^{\text {[a] }}$ \\ Axel Knödler, ${ }^{\mid \mathrm{a}][\neq 1}$ and Ingo Hartenbach ${ }^{[\mathrm{a} \mid[\neq 1}$
}

\begin{abstract}
We describe the allenylidene complexes $\left[\mathrm{TpL}_{2} \mathrm{Ru}=\mathrm{C}=\mathrm{C}=\right.$ $\mathrm{CPhR}]^{+} \mathrm{SbF}_{6}{ }^{-}\left[\mathrm{Tp}=\mathrm{HB}(\mathrm{pz})_{3}{ }^{-}, \mathrm{L}_{2}=2 \mathrm{PPh}_{3}\right.$ or $1,1^{\prime}$-bis(diphenylphosphanyl)ferrocene (dppf), $\mathrm{R}=\mathrm{Ph}$ or ferrocenyl] and their spectroscopic and electrochemical characteristics. Three of these compounds possess redox-active, ferrocenebased substituents or ligands - that are oxidized at lower potentials than the ruthenium center itself - attached either to the terminal carbon atom of the allenylidene ligand or to the ruthenium atom. The Fc/Ph-substituted complexes $\mathbf{3 a}$ and $\mathbf{3 b}$ provide unique examples of hindered rotation of the allenylidene substituent around the $\mathrm{M}=\mathrm{C}$ bond. For 3a $\left(\mathrm{L}_{2}=2 \mathrm{PPh}_{3}\right)$, two isomers differing in the orientation of the vertically aligned, unsymmetrically substituted allenylidene ligand are discernible even at $388 \mathrm{~K}$. The dppf-substituted congener $\mathbf{3 b}$ has the allenylidene ligand in a horizontal orientation and exhibits a rotational barrier, as determined by dynamic ${ }^{31} \mathrm{P}$ NMR spectroscopy, of $\Delta G^{*}=47 \mathrm{~kJ} / \mathrm{mol}$ at $T_{\mathrm{C}}=238 \mathrm{~K}$. The changes in the spectroscopic and electrochemical properties upon replacement of the $\mathrm{PPh}_{3}$ by a dppf ligand and the $\mathrm{Ph}$ by an Fc moiety can be explained in terms of the bonding within these systems. These effects are attenuated when the ferrocene-based redox tags are oxidized, as shown by IR and
\end{abstract}

\section{Introduction}

In connection with our interest in the reactivity of primary butatrienylidene intermediates trans $-\left[\mathrm{Cl}\left(\mathrm{L}_{2}\right)_{2} \mathrm{Ru}=\mathrm{C}=\right.$ $\left.\mathrm{C}=\mathrm{C}=\mathrm{CH}_{2}\right]^{+}\left(\mathrm{L}_{2}\right.$ = chelating diphosphane ligand $)$ we have established new routes to heteroatom-substituted allenylidene complexes trans- $\left[\mathrm{Cl}\left(\mathrm{L}_{2}\right)_{2} \mathrm{Ru}=\mathrm{C}=\mathrm{C}=\mathrm{C}\left(\mathrm{ER}_{n}\right)\left(\mathrm{R}^{\prime}\right)\right]^{+}$, in part with unprecedented $\left(\mathrm{ER}_{n}=\mathrm{SR}, \mathrm{SeR}\right)$ substitution patterns. ${ }^{[1,2]}$ These rely either on the regioselective addition of protic nucleophiles to the terminal $\mathrm{C}=\mathrm{C}$ double bond of the unsaturated ligand or on the regioselective addition of aprotic, allyl-substituted nucleophiles to carbon atom C- $\gamma$. In this latter case, the initial addition is followed by a Copetype rearrangement of the resulting 3-heterohexa-1,5-diene moiety. ${ }^{[1-4]}$ The former approach had also been employed by Bruce and others in the synthesis of amino-substituted allenylidene complexes $\left[\mathrm{Cp}\left(\mathrm{PPh}_{3}\right)_{2} \mathrm{Ru}=\mathrm{C}=\mathrm{C}=\mathrm{C}\left(\mathrm{NR}_{2}\right)\right.$ -

\footnotetext{
[a] Institut für Anorganische Chemie der Universität Stuttgart, Pfaffenwaldring 55, 70569 Stuttgart, Germany

E-mail: winter@iac.uni-stuttgart.de

[t] X-ray structure determination
}

UV/Vis spectroelectrochemistry. Thus, infrared spectroelectrochemistry reveals a blue shift of the allenylidene stretch upon oxidation of the dppf ligand, while oxidation of the ferrocene covalently linked to the unsaturated $\mathrm{C}_{3}$ ligand has the opposite effect. Oxidation of the ruthenium atom influences the bonding within the unsaturated ligand more profoundly. Results from IR spectroelectrochemistry point to a vinylidene structure in the $\mathrm{Ru}^{\mathrm{III}}$ state. Reduction enhances the contribution of alkynyl-type resonance forms to the overall bonding description, as also shown by IR spectroelectrochemistry. For the ferrocenyl-substituted allenylidene complexes, oxidation and reduction result in bleaching of the intense optical low-energy absorption band attributed to a ferrocenyl-to-allenylidene charge-transfer process. The EPR spectra of the paramagnetic reduced forms of these complexes also indicate spin delocalization into the aryl substituents attached to the allenylidene ligand. The complexes $\mathrm{Tp}(\mathrm{dppf}) \mathrm{RuCl}$ and $\left[\mathrm{Tp}(\mathrm{dppf}) \mathrm{Ru}=\mathrm{C}=\mathrm{C}=\mathrm{CPh}_{2}\right]^{+} \mathrm{SbF}_{6}{ }^{-}$were also characterized by $\mathrm{X}$-ray crystallography.
$\left.\left(\mathrm{CH}_{3}\right)\right]^{+}{ }^{[5,6]}$ and the related alkoxy-substituted iron derivative $\left[\mathrm{Cp}^{*}(\mathrm{dppe}) \mathrm{Fe}=\mathrm{C}=\mathrm{C}=\mathrm{C}\left(\mathrm{OCH}_{3}\right)\left(\mathrm{CH}_{3}\right)\right]^{+} \cdot{ }^{[7]}$ Characteristic attributes of allenylidene complexes include: (i) the asymmetric valence band known as the "allenylidene stretch", giving rise to highly intense absorption bands in their infrared spectra, (ii) low-field signals for the carbon atoms of the unsaturated ligands in their ${ }^{13} \mathrm{C}$ NMR spectra, ${ }^{[4,8]}$ and (iii) their optical spectra, which feature two bands in the visible region. The band at lower energy is due to the forbidden HOMO $\rightarrow$ LUMO transition and so is only weak, while that at higher energy is much more intense and represents the allowed transition from the lower lying second-highest occupied molecular orbital HOMO-1. Systematic studies on the complexes trans $-\left[\mathrm{Cl}\left(\mathrm{L}_{2}\right)_{2} \mathrm{Ru}=\mathrm{C}=\mathrm{C}=\right.$ $\left.\mathrm{C}\left(\mathrm{ER}_{n}\right)\left(\mathrm{R}^{\prime}\right)\right]^{+}$revealed that their spectroscopic and electrochemical properties critically depend on the substituent $\mathrm{ER}_{n}\left(\mathrm{ER}_{n}=\mathrm{NR}_{2}, \mathrm{SR}, \mathrm{SeR}\right.$, aryl $)$ and the diphosphane ligands $L_{2}$. Replacement of amino substituents $N_{2}$ by the less potent $\pi$-donors $\mathrm{SR}, \mathrm{SeR}$, or aryl groups induces a systematic red shift of the electronic and infrared absorption bands and a low-field shift of the resonance signals of the 
metal-bound carbon atom $C-\alpha$ and the carbon atom $C-\beta$ adjacent to it. ${ }^{[1.2]}$ Electrochemical investigations by cyclic voltammetry revealed a cathodic displacement of the halfwave potentials of the reduction and, albeit only to a minor degree, of the oxidation potentials upon substitution of $\mathrm{NR}_{2}$ by $\mathrm{SR}, \mathrm{SeR}$, or aryl moieties. Broadly similar effects are observed when the $\pi$-acidity of the diphosphane chelate ligands is decreased. This mirrors the push-pull characteristics of these complexes, with the $\mathrm{ClRu}\left(\mathrm{L}_{2}\right)_{2}{ }^{+}$moiety acting as the donor and the allenylidene unit as the acceptor. One remarkable difference between the effects concomitant with ligand and substituent replacement is their effect redox potentials: replacement of the $\pi$-acidic ligands dppe and dppm by the more basic depe facilitates oxidation by more than $300 \mathrm{mV}$ but leaves the reduction potential essentially unchanged. This has been taken as an indication of a ruthenium-based oxidation but a largely allenylidene-based reduction. Spectroelectrochemical experiments, monitoring the spectroscopic changes associated with bulk electrolysis by IR, UV/Vis, and EPR techniques, and results from quantum mechanical calculations strongly support this view. ${ }^{[1,4.9-11]}$

We have now turned our attention to allenylidene complexes with either an additional redox-active moiety attached to the $\mathrm{C}_{3}$ ligand or a redox-active diphosphane ligand. These were chosen such that they would undergo reversible electron transfer at lower potentials than the parent allenylidene complex itself. This was to allow examination of the effect of variation of the electron density at each of these sites within the same basic system, without the need for additional ligand or substituent replacement. Since structural perturbations of the metallabutatriene chromophore associated with electron transfer at a peripheral site would be expected to be reasonably limited, the results from such studies should reflect the effects of changes in the electron density at these sites more truly than any substitution. In this respect, ferrocenyl-based systems are ideal candidates, as they are known to undergo facile and reversible oxidation at substantially lower potentials than the $\mathrm{Ru}^{\mathrm{II} / \mathrm{III}}$ couple. We have already reported on the ferrocenyl-substituted allenylidene complexes trans $-\left[\mathrm{Cl}(\mathrm{dppm})_{2} \mathrm{Ru}=\mathrm{C}=\mathrm{C}=\right.$ $\left.\mathrm{C}\left(\mathrm{NMe}_{2}\right)\left(\mathrm{C}_{2} \mathrm{H}_{4} \mathrm{Fc}\right)\right]^{+}\left[\mathrm{Fc}=\left(\eta^{5}-\mathrm{C}_{5} \mathrm{H}_{4}\right) \mathrm{Fe}\left(\eta^{5}-\mathrm{C}_{5} \mathrm{H}_{5}\right)\right]^{[12]}$ and trans $-\left[\mathrm{Cl}(\mathrm{dppm})_{2} \mathrm{Ru}=\mathrm{C}=\mathrm{C}=\mathrm{C}(\mathrm{SeFc})\left(\mathrm{C}_{2} \mathrm{H}_{4} \mathrm{CH}=\mathrm{CH}_{2}\right)\right]^{+}$. ${ }^{[2]}$ In the amino-substituted complex the insulating ethylene spacer separating the allenylidene chromophore from the redox-active ferrocenyl unit prevents effective conjugation between these entities. The spectroscopic changes associated with ferrocene oxidation are therefore small. In the selenosubstituted allenylidene complex, the redox-active group is directly attached to the heteroatom. Electron transfer from this site induces more substantial spectroscopic changes, with a red shift of the IR frequency by $10 \mathrm{~cm}^{-1}$. Here we present our results on a different class of allenylidene complexes based on $\mathrm{TpRuL}_{2}$ units, as pioneered by Puerta and Hill $\left[\mathrm{Tp}=\mathrm{HB}(\mathrm{pz})_{3}{ }^{-}\right.$, tris(pyrazolyl)borate]. ${ }^{[13-15]}$ These complexes offer the opportunity to introduce ferrocenebased redox tags either into the allenylidene ligand or into the diphosphane chelate ligand - or into both - while maintaining the same overall structure. We compare our results for these systems with those for the corresponding "parent" diphenylallenylidene complex $\left[\mathrm{Tp}\left(\mathrm{PPh}_{3}\right)_{2} \mathrm{Ru}=\mathrm{C}=\right.$ $\left.\mathrm{C}=\mathrm{CPh}_{2}\right]^{+}$, which lacks any additional redox-active moiety, as a reference system. ${ }^{[13]}$

\section{Results and Discussion}

\section{Synthesis, Molecular Structures, and Spectroscopic Properties}

The synthesis of allenylidene complexes containing the $\left[\mathrm{TpRuL}_{2}\right]$ moiety is straightforward and follows the method elaborated by Hill and co-workers. ${ }^{[13]}$ Treatment of a $\mathrm{CH}_{2} \mathrm{Cl}_{2}$ solution of $\left[\mathrm{TpRuL}{ }_{2} \mathrm{Cl}\right]\left(\mathrm{L}_{2}=2 \mathrm{PPh}_{3}: \mathbf{1 a} ; \mathrm{L}_{2}=\right.$ dppf: 1b) with the appropriate propargylic alcohol $\mathrm{PhR}(\mathrm{OH}) \mathrm{CC} \equiv \mathrm{CH}\left[\mathrm{R}=\mathrm{Ph}, \mathrm{Fc} ; \mathrm{Fc}=\left(\eta^{5}-\mathrm{C}_{5} \mathrm{H}_{4}\right) \mathrm{Fe}\left(\eta^{5}-\right.\right.$ $\left.\left.\mathrm{C}_{5} \mathrm{H}_{5}\right)\right]$ in the presence of $\mathrm{AgSbF}_{6}$ gave the corresponding cationic allenylidene complexes $\left[\mathrm{TpL}_{2} \mathrm{Ru}=\mathrm{C}=\mathrm{C}=\mathrm{CRPh}\right]^{+}$ $(\mathbf{2} \mathbf{a}-\mathbf{3 b})$ in good to reasonable yields and as intensely purple-colored, microcrystalline solids (Scheme I). In the course of these syntheses we obtained single crystals of $[\mathrm{Tp}(\mathrm{dppf}) \mathrm{RuCl}]$ and the corresponding diphenyl-substituted allenylidene complex $\left[\mathrm{Tp}(\mathrm{dpp}) \mathrm{Ru}=\mathrm{C}=\mathrm{C}=\mathrm{CPh}_{2}\right]^{+}$(2b). Their molecular structures in the solid state were established by X-ray crystallography and are presented in Figures $1-3$, while selected bond parameters are provided in Tables 1 and 2.

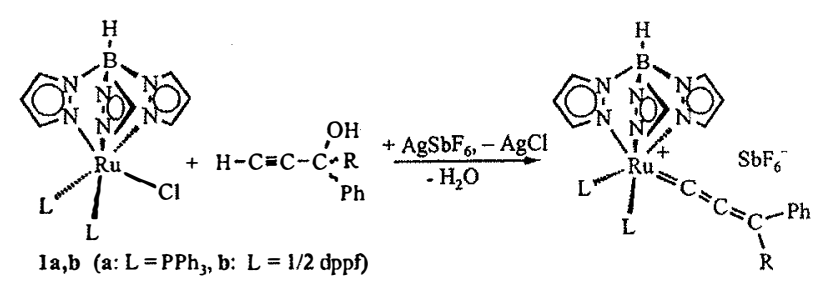

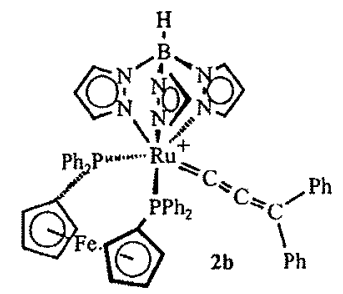
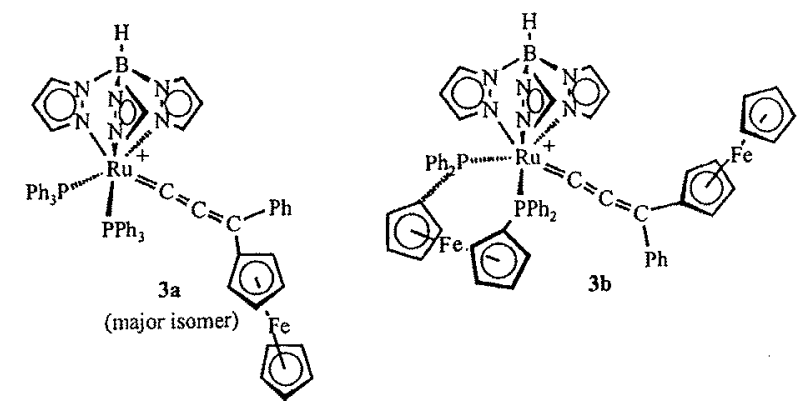

Scheme 1 


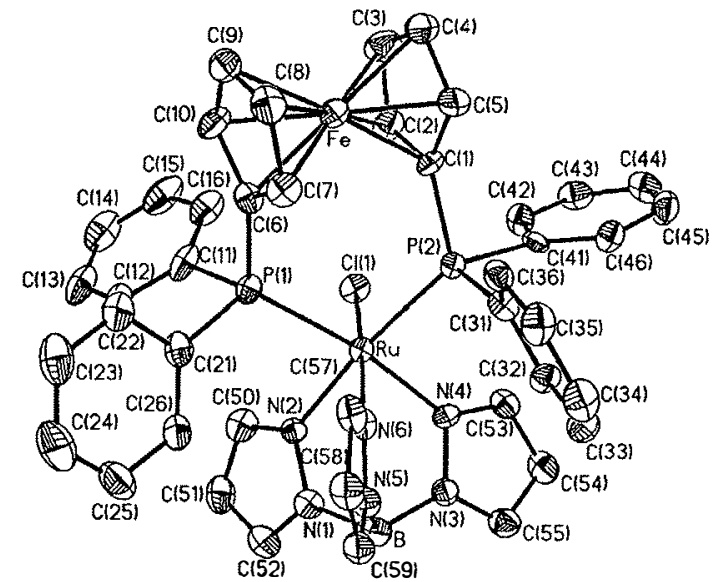

Figure 1. Structure of $[\mathrm{Tp}(\mathrm{dppf}) \mathrm{RuCl}]$ in the solid state

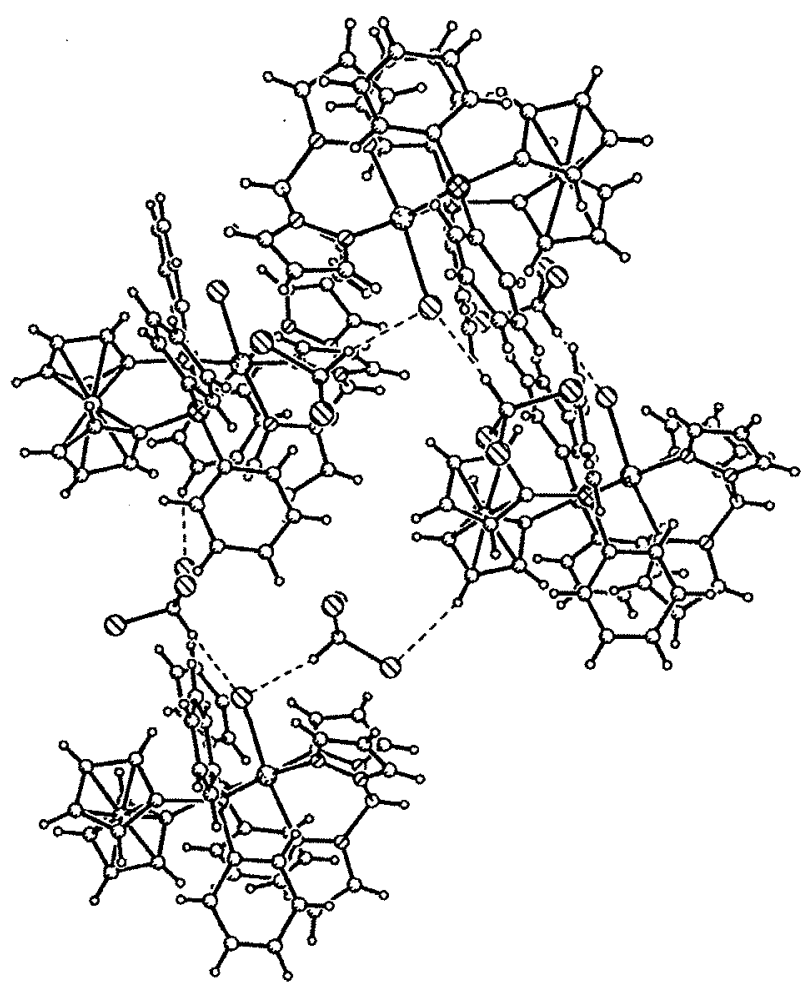

Figure 2. Intermolecular contacts between the chloride ligand and the solvate molecules of $[\mathrm{Tp}(\mathrm{dppf}) \mathrm{RuCl}]$

[Tp(dppf)RuCl] (1b) crystallizes as a bis(solvate) from chloroform, and a plot of its structure is presented as Figure 1 . Complex $\mathbf{1 b}$ displays bond parameters (Table 1) very similar to those of the $\mathrm{PPh}_{3}$-substituted congener. ${ }^{[17]}$ The $\mathrm{P}(1)-\mathrm{Ru}-\mathrm{P}(2)$ bite angle of the chelating dppf ligand is only slightly smaller than the $\mathrm{P}-\mathrm{Ru}-\mathrm{P}$ angle in the other complex [99.23(6) against $\left.101.9(1)^{\circ}\right]$ and induces a compression of the opposite angle $\mathrm{N}(2)-\mathrm{Ru}-\mathrm{N}(4)$ to $81.9(2)^{\circ}$. All other angles between cis-disposed ligands are in the $85.0-93.8^{\circ}$ range, while mutually trans-disposed ligands make angles of approximately $171^{\circ}$ at the metal atom.

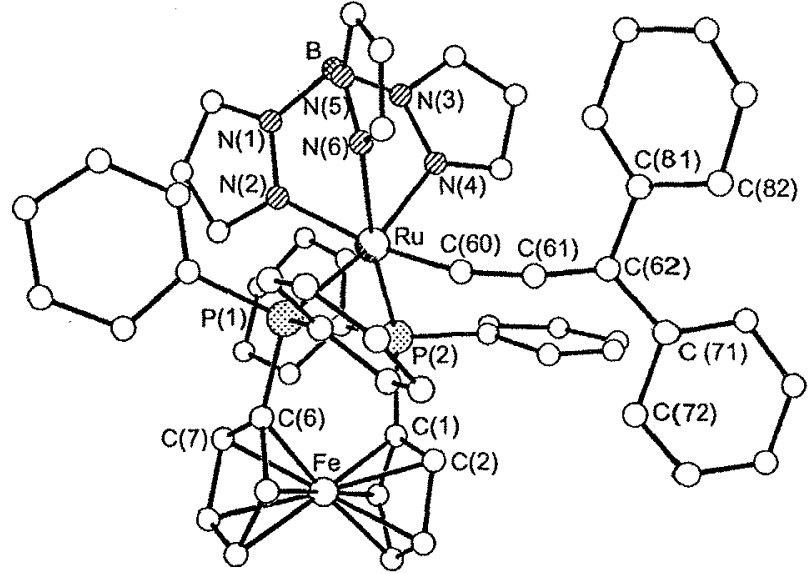

Figure 3. Structure of $\left[\mathrm{Tp}(\mathrm{dppf}) \mathrm{Ru}=\mathrm{C}=\mathrm{C}=\mathrm{CPh}_{2}\right]^{+}$in the solid state

Table 1. Selected bond lengths $[\AA]$ and bond angles $\left[^{\circ}\right]$ for $[\mathrm{Tp}-$ (dppf)RuCl] (1b)

\begin{tabular}{llll}
\hline $\mathrm{Ru}-\mathrm{N}(2)$ & $2.144(5)$ & $\mathrm{N}(4)-\mathrm{Ru}-\mathrm{N}(2)$ & $81.86(19)$ \\
$\mathrm{Ru}-\mathrm{N}(4)$ & $2.144(5)$ & $\mathrm{N}(6)-\mathrm{Ru}-\mathrm{N}(2)$ & $87.57(19)$ \\
$\mathrm{Ru}-\mathrm{N}(6)$ & $2.099(5)$ & $\mathrm{N}(6)-\mathrm{Ru}-\mathrm{N}(4)$ & $87.60(19)$ \\
$\mathrm{Ru}-\mathrm{P}(1)$ & $2.3503(16)$ & $\mathrm{N}(2)-\mathrm{Ru}-\mathrm{P}(1)$ & $89.70(14)$ \\
$\mathrm{Ru}-\mathrm{P}(2)$ & $2.3362(16)$ & $\mathrm{N}(6)-\mathrm{Ru}-\mathrm{P}(1)$ & $89.34(15)$ \\
$\mathrm{Ru}-\mathrm{Cl}(1)$ & $2.4200(16)$ & $\mathrm{N}(4)-\mathrm{Ru}-\mathrm{P}(1)$ & $171.13(14)$ \\
$\mathrm{Fe}-\mathrm{C}(1)$ & $2.001(6)$ & $\mathrm{N}(4)-\mathrm{Ru}-\mathrm{P}(2)$ & $89.27(14)$ \\
$\mathrm{Fe}-\mathrm{C}(2)$ & $2.018(7)$ & $\mathrm{N}(6)-\mathrm{Ru}-\mathrm{P}(2)$ & $93.59(14)$ \\
$\mathrm{Fe}-\mathrm{C}(3)$ & $2.063(7)$ & $\mathrm{N}(2)-\mathrm{Ru}-\mathrm{P}(2)$ & $171.00(14)$ \\
$\mathrm{Fe}-\mathrm{C}(4)$ & $2.084(7)$ & $\mathrm{P}(2)-\mathrm{Ru}-\mathrm{P}(1)$ & $99.23(6)$ \\
$\mathrm{Fe}-\mathrm{C}(5)$ & $2.052(7)$ & $\mathrm{P}(1)-\mathrm{Ru}-\mathrm{Cl}$ & $93.83(6)$ \\
$\mathrm{Fe}-\mathrm{C}(6)$ & $2.009(6)$ & $\mathrm{P}(2)-\mathrm{Ru}-\mathrm{Cl}$ & $93.28(6)$ \\
$\mathrm{Fe}-\mathrm{C}(7)$ & $2.013(7)$ & $\mathrm{N}(2)-\mathrm{Ru}-\mathrm{Cl}$ & $84.98(14)$ \\
$\mathrm{Fe}-\mathrm{C}(8)$ & $2.061(7)$ & $\mathrm{N}(4)-\mathrm{Ru}-\mathrm{Cl}$ & $88.15(14)$ \\
$\mathrm{Fe}-\mathrm{C}(9)$ & $2.061(7)$ & $\mathrm{N}(6)-\mathrm{Ru}-\mathrm{Cl}$ & $171.87(14)$ \\
$\mathrm{Fe}-\mathrm{C}(10)$ & $2.032(7)$ & $\mathrm{P}(2)-\mathrm{Ru}-\mathrm{P}(1)$ & $99.23(6)$ \\
$\mathrm{P}(1)-\mathrm{C}(6)$ & $1.835(6)$ & $\mathrm{P}(1)-\mathrm{Ru}-\mathrm{Cl}$ & $93.83(6)$ \\
$\mathrm{P}(1)-\mathrm{C}(11)$ & $1.850(7)$ & $\mathrm{P}(2)-\mathrm{Ru}-\mathrm{Cl}$ & $93.28(6)$ \\
$\mathrm{P}(2)-\mathrm{C}(1)$ & $1.807(6)$ & & \\
$\mathrm{P}(2)-\mathrm{C}(31)$ & $1.823(6)$ & & \\
$\mathrm{P}(2)-\mathrm{C}(41)$ & $1.862(6)$ & & \\
\hline
\end{tabular}

Table 2. Selected bond lengths $[\AA]$ and bond angles $\left[^{\circ}\right]$ for $\left[\mathrm{Tp}(\mathrm{dppf}) \mathrm{Ru}\left(=\mathrm{C}=\mathrm{C}=\mathrm{CPh}_{2}\right)\right] \mathrm{SbF}_{6}(\mathbf{2 b})$

\begin{tabular}{llll}
\hline $\mathrm{Ru}-\mathrm{P}(1)$ & $2.416(9)$ & $\mathrm{P}(1)-\mathrm{Ru}-\mathrm{P}(2)$ & $99.1(3)$ \\
$\mathrm{Ru}-\mathrm{P}(2)$ & $2.376(11)$ & $\mathrm{P}(1)-\mathrm{Ru}-\mathrm{C}(60)$ & $94.7(11)$ \\
$\mathrm{Ru}-\mathrm{N}(2)$ & $2.16(3)$ & $\mathrm{P}(2)-\mathrm{Ru}-\mathrm{C}(60)$ & $92.1(11)$ \\
$\mathrm{Ru}-\mathrm{N}(4)$ & $2.18(3)$ & $\mathrm{N}(2)-\mathrm{Ru}-\mathrm{N}(4)$ & $84.8(10)$ \\
$\mathrm{Ru}-\mathrm{N}(6)$ & $2.20(3)$ & $\mathrm{N}(2)-\mathrm{Ru}-\mathrm{N}(6)$ & $85.5(10)$ \\
$\mathrm{Ru}-\mathrm{C}(60)$ & $1.88(4)$ & $\mathrm{N}(4)-\mathrm{Ru}-\mathrm{N}(6)$ & $81.8(11)$ \\
$\mathrm{C}(60)-\mathrm{C}(61)$ & $1.32(5)$ & $\mathrm{P}(1)-\mathrm{Ru}-\mathrm{N}(2)$ & $89.3(7)$ \\
$\mathrm{C}(61)-\mathrm{C}(62)$ & $1.26(5)$ & $\mathrm{P}(1)-\mathrm{Ru}-\mathrm{N}(4)$ & $169.2(8)$ \\
$\mathrm{C}(61)-\mathrm{C}(71)$ & $1.46(5)$ & $\mathrm{P}(1)-\mathrm{Ru}-\mathrm{N}(6)$ & $88.8(8)$ \\
$\mathrm{C}(61)-\mathrm{C}(81)$ & $1.52(5)$ & $\mathrm{P}(2)-\mathrm{Ru}-\mathrm{N}(2)$ & $95.2(7)$ \\
& & $\mathrm{P}(2)-\mathrm{Ru}-\mathrm{N}(4)$ & $90.5(8)$ \\
& & $\mathrm{P}(2)-\mathrm{Ru}-\mathrm{N}(6)$ & $172.2(8)$ \\
& & $\mathrm{Ru}-\mathrm{C}(60)-\mathrm{C}(61)$ & $168(3)$ \\
& & $\mathrm{C}(60)-\mathrm{C} 61)-\mathrm{C}(62)$ & $168(4)$ \\
\hline
\end{tabular}


The close similarity between [Tp(dppf RuCl] and $\left[\mathrm{Tp}\left(\mathrm{PPh}_{3}\right)_{2} \mathrm{RuCl}\right]$ is also evident from the essentially identical $\mathrm{Ru}-\mathrm{P}$ and $\mathrm{Ru}-\mathrm{Cl}$ bond lengths in these two complexes [2.336(2), 2.350(2) and 2.420(2) against 2.332(3), 2.349(3) and $2.409(3) \AA$ ]. As is often observed for complexes of the Tp ligand, ${ }^{[13,18,19]}$ the nitrogen atom trans to the chloride ligand is closer to the metal center than those opposite to the $\pi$-accepting phosphane ligands. Both the cyclopentadienyl $(\mathrm{Cp})$ rings of the dppf ligand are essentially planar, and the phosphorus atoms are situated in the plane of the ring to which they are attached. The ring centroids and the $\mathrm{Fe}$ atom make an angle of $178.2^{\circ}$, while the two rings adopt a staggered conformation and are rotated by $38^{\circ}$ with respect to one another. The packing in the crystal lattice is stabilized by several inter- and intramolecular hydrogen bonds involving the solvate molecules, the chloride ligand, some nitrogen atoms of the pyrazolyl rings, and one hydrogen atom of each phenyl ring, as well as one of the Cp-hydrogen atoms of the dppf ligand. Intramolecular hydrogen bonds of 2.528 and $2.663 \AA$ are observed between the ortho-hydrogen atom attached to $\mathrm{C}(26)$ and the nitrogen atoms $\mathrm{N}(1)$ and $\mathrm{N}(2)$. A similar contact is found for $\mathrm{H}(32 \mathrm{a})$ - the hydrogen atom at $\mathrm{C}(32)$ - and N(4) (2.677 $\AA$ ). The chloride ligand forms a pair of contacts to one of the orthohydrogen atoms of each of the adjacent phenyl rings, with a fairly short bond of $2.590 \AA$ to $\mathrm{H}(42)$ and a weaker contact of $2.871 \AA$ to $\mathrm{H}(16)$ on the other phenyl ring. The chloride ligand also forms strong intermolecular contacts to the protons of the two cocrystallized $\mathrm{CHCl}_{3}$ solvate molecules, as evidenced by $\mathrm{H} \cdots \mathrm{Cl}$ distances of 2.393 and 2.423 $\AA$. The solute molecules are additionally fixed through weaker interactions to hydrogen atoms on the aromatic substituents. Thus, one chloroform molecule makes a contact of $2.834 \AA$ to one of the phenyl protons, while the other is $2.792 \AA$ away from $\mathrm{H}(8 \mathrm{a})$ at the 3-position of one of the $\mathrm{Cp}$ rings of the dppf ligand. Additional weaker interactions are observed between the other chlorine atoms of the cocrystallized solvent molecules and hydrogen atoms $\mathrm{H}(13)[3.292 \AA$ to $\mathrm{Cl}(5), 3.249 \AA$ to $\mathrm{Cl}(7)], \mathrm{H}(14)[3.247 \AA$ to $\mathrm{Cl}(2), 3.289$ $\AA$ to $\mathrm{Cl}(4)$ ], and $\mathrm{H}(43)$ [3.274 $\AA$ to $\mathrm{Cl}(3)$ ] on the phenyl rings as well as to $\mathrm{H}(9)[3.175 \AA$ to $\mathrm{Cl}(6)]$ on the $\mathrm{Cp}$ ring. The H-bridges resulting from the stronger intermolecular $\mathrm{H} \cdot \cdots \mathrm{Cl}$ contacts are shown in Figure 2.

The diphenylallenylidene complexes $\mathbf{2 a}$ and $\mathbf{2 b}$, including the solid-state structure of compound $2 a$, have already been reported by Hill. ${ }^{[13]}$ We were able to obtain single crystals of the dppf-substituted congener $\mathbf{2} \mathbf{b}$, but these gave a data set of only poor quality, preventing meaningful discussion of bond lengths and angles within the allenylidene chain. We only note that, as in the chloro precursors $\mathbf{1 a}$ and $\mathbf{1 b}$, the $\mathrm{Ru}-\mathrm{P}$ bond lengths and the $\mathrm{P}-\mathrm{Ru}-\mathrm{P}$ angles are nearly identical for both allenylidene complexes [2.376(11) and 2.416(9) against $2.3779(7)$ and $2.4327(11) \AA$ as well as 99.1(3) against $\left.101.11(3)^{\circ}\right]$. We also note that the terminal $\mathrm{CPh}_{2}$ group of the allenylidene ligand lies approximately in the mirror plane of the molecule [the torsional angle $\mathrm{N}(2)-\mathrm{Ru}-\mathrm{C}(62)-\mathrm{C}(81)$ is $18.5^{\circ}$ ] and roughly bisects the $\mathrm{P}-\mathrm{Ru}-\mathrm{P}$ angle. This orientation has been termed vertical.
A plot of the structure is provided as Figure 3, while the most pertinent bond parameters are collected in Table 2 .

Complexes $\mathbf{2 a}$ and $\mathbf{2 b}$ and their Fc-substituted congeners $\mathbf{3 a}$ and $\mathbf{3 b}$ have very similar spectroscopic characteristics in their IR and NMR spectra. These are compared in Table 3. Samples (as $\mathrm{KBr}$ pellets) display the $\mathrm{C}=\mathrm{C}=\mathrm{C}$ stretch of the unsaturated ligand as a very intense band at $1946 \mathrm{~cm}^{-1}$ for 3a and at $1941 \mathrm{~cm}^{-1}$ for $3 \mathbf{b}$, which are some $5 \mathrm{~cm}^{-1}$ higher in energy than in the diphenyl-substituted complexes 2a and 2b (see also Table 3). Replacement of the dppf by the less basic $\mathrm{PPh}_{3}$ ligands induces a blue shift of similar size. The observed effects, albeit small, match previous observations that the presence of a weaker $\pi$-donor at the terminal carbon atom $\mathrm{C}-\gamma$ (phenyl versus ferrocenyl) or of a more basic metal center at the opposite end of the metallabutatriene chain (the dppf versus two $\mathrm{PPh}_{3}$ ligands) shifts the IR absorption of the allenylidene ligand to lower energies. This has been explained in terms of a larger contribution from the alkynyl-type resonance form II as opposed to the genuine cumulenylidene-type resonance form I (Scheme 2) when the metal center is more electron-rich and the substituents at $\mathrm{C}-\gamma$ are less able to support a positive charge adjacent to them. ${ }^{[1,2,4,20,21]}$ In the light of the stability of the ferrocenylmethylene carbenium ion ${ }^{[22]}$ the ferrocenyl substituent may be expected to stabilize the alternative alkynyl resonance form III, as indicated in Scheme 2, in line with the results from IR spectroscopy. We note here that Le Bozec et al. arrived at a similar conclusion in their study of $\left[\left(\mathrm{C}_{6} \mathrm{Me}_{6}\right)\right.$ $\left.\mathrm{Cl}\left(\mathrm{PMe}_{3}\right) \mathrm{Ru}=\mathrm{C}=\mathrm{C}=\mathrm{C}(\mathrm{Ph})(\mathrm{Fc})\right]^{+} \mathrm{PF}_{6}{ }^{-}$, closely related to 3a and 3b. ${ }^{[23]}$ The ${ }^{13} \mathrm{C}$ NMR spectra also bear witness to this notion. Comparison of the relevant data for the pairs of complexes $2 \mathbf{a} / \mathbf{3} \mathbf{a}$ and $\mathbf{2 b} / \mathbf{3 b}$ reveals that replacement of a phenyl by the more strongly electron-donating ferrocenyl substituent shifts the resonance signals of the carbon atoms of the allenylidene ligand to higher field by ca. 30, 25, and $8 \mathrm{ppm}$. The largest shift is observed for the metal-coordinated carbon atom $\mathrm{C}-\alpha$, while the terminal carbon atom $\mathrm{C}$ $\gamma-$ where the actual substitution occurs - is influenced least. The sign and relative magnitude of the observed effects agree well with results from previous studies on the allenylidene complexes trans $-\left[\mathrm{Cl}\left(\mathrm{L}_{2}\right){ }_{2} \mathrm{Ru}=\mathrm{C}=\mathrm{C}=\right.$ $\left.\mathrm{C}\left(\mathrm{ER}_{n}\right)\left(\mathrm{R}^{\prime}\right)\right]^{+}\left(\mathrm{ER}_{n}=\mathrm{NR}_{2}, \mathrm{SR}, \mathrm{SeR}\right.$, aryl, $\mathrm{R}^{\prime}=$ alkyl) ${ }^{[1,4,24]}$

The triphenylphosphane-substituted complex $\mathbf{3 a}$ was found to exist as two isomers, as shown by the two sets of resonance signals for the carbon atoms of the cumulenylidene ligand. These are observed at $\delta=287.0,184.3$, and $168.2 \mathrm{ppm}$ for the major isomer and $\delta=282.8,180.5$ and $169.1 \mathrm{ppm}$ for the minor counterpart, and point to hindered rotation of the allenylidene ligand around the $\mathrm{Ru}=\mathrm{C}$ bond. Each isomer exhibits a singlet resonance signal in the ${ }^{31} \mathrm{P}$ NMR spectrum. We therefore conclude that the plane of the terminal $\mathrm{CR}_{2}$ unit of the allenylidene ligand runs parallel to the molecular symmetry plane and bisects the $\mathrm{P}-\mathrm{Ru}-\mathrm{P}$ angle, an orientation that has been termed vertical. ${ }^{[25]}$ Scheme 3 offers a Newman-type projection along the $\mathrm{Ru}=\mathrm{C}=\mathrm{C}=\mathrm{C}$ axis. The isomers differ in which of the $\mathrm{Ph}$ or the Fc substituents points toward the $\mathrm{Tp}$ and the 
Table 3. Selected spectroscopic data for complexes $\mathbf{2} \mathbf{a}-\mathbf{3 b}$

\begin{tabular}{|c|c|c|c|c|c|c|c|}
\hline Compd. & $\begin{array}{l}{ }^{31} \mathrm{P} \text { NMR: } \\
\delta[\mathrm{ppm}]\end{array}$ & $\begin{array}{l}{ }^{13} \mathrm{C} \text { NMR: } \\
\delta[\mathrm{ppm}] \\
\mathrm{C}-\alpha\end{array}$ & $C-\beta$ & $C-\gamma$ & $\begin{array}{l}\text { IR }(\mathrm{KBr}): \\
\tilde{v}(\mathrm{C}=\mathrm{C}=\mathrm{C})\left[\mathrm{cm}^{-1}\right]\end{array}$ & $\begin{array}{l}\text { UV/Vis: } \\
\lambda_{\max }[\mathrm{nm}](\log \varepsilon)^{[\mathrm{aa}]} \\
\text { HOMO-1 } \rightarrow \text { LUMO }\end{array}$ & $\mathrm{HOMO} \rightarrow \mathrm{LUMO}$ \\
\hline $2 a$ & 36.6 & 316.6 & 208.9 & 160.9 & 1941 & $527(4.217)$ & $907(2.820)$ \\
\hline $2 b$ & 30.2 & 316.2 & 208.3 & 161.3 & 1936 & $522(4.204)$ & $902(2.763)$ \\
\hline \multirow[t]{2}{*}{$3 \mathbf{a}$} & $40.8^{[\mathrm{b}]}$ & $287.0^{[\mathrm{b}]}$ & $184.3^{[b]}$ & $168.2^{[\mathrm{b}]}$ & 1946 & $538(4.061)$ & $-[d]$ \\
\hline & $40.5^{[c]}$ & $282.8^{[\mathrm{c}]}$ & $180.5^{[\mathrm{c}]}$ & $169.1^{[\mathrm{c}]}$ & & & \\
\hline $3 b$ & 29.9 & 283.7 & 180.6 & 167.9 & 1941 & $540(4.190)$ & $-[d]$ \\
\hline
\end{tabular}

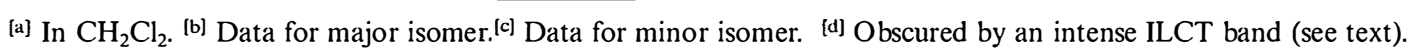
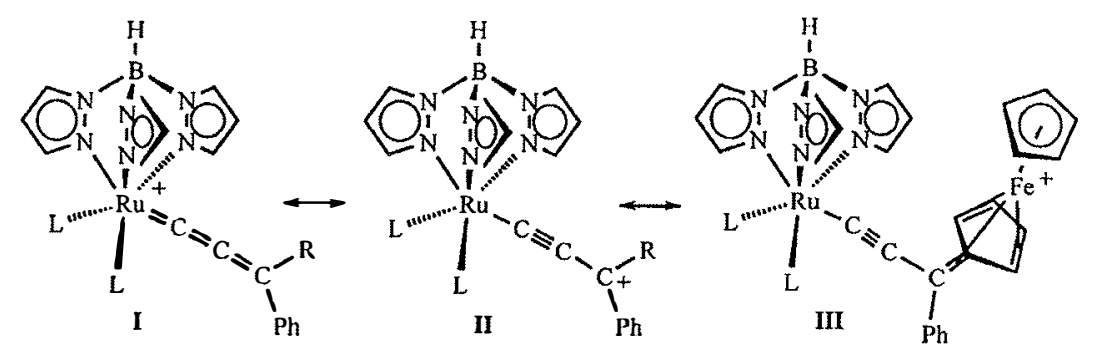

Scheme 2

phosphane ligands. We propose that the major isomer has the less bulky phenyl substituent oriented toward the $\mathrm{PPh}_{3}$ ligands. By integration of the ${ }^{31} \mathrm{P}$ NMR resonance signals the isomeric distribution was established as 4:1. Unfortunately, we have not yet succeeded in growing $X$-ray quality crystals of this complex to support this view. We note, however, that both $\left[\mathrm{Tp}\left(\mathrm{PPh}_{3}\right)_{2} \mathrm{Ru}=\mathrm{C}=\mathrm{C}=\mathrm{CPh}_{2}\right]^{+} \mathrm{PF}_{6}^{-}$(2a) and its dppf analogue $\mathbf{2 b}$ (vide supra) crystallize with the allenylidene ligand in just this orientation. ${ }^{[13]}$
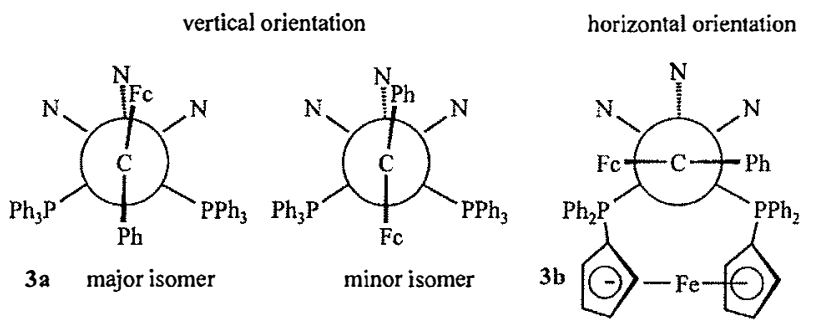

Scheme 3

To the best of our knowledge, complex 3a represents the first instance of an allenylidene complex in which the energy barrier to rotation of the allenylidene moiety is so high as to allow observation of two different rotamers at ambient temperature. Hindered rotations around $\mathrm{M}=\mathrm{C}$ double bonds have, however, been noted in the related vinylidene complexes $\{\mathrm{M}\}=\mathrm{C}=\mathrm{CR}_{2} \cdot{ }^{[26-28]}$ Experimentally measured energy barriers are usually of the order of $30-57 \mathrm{~kJ} / \mathrm{mol}$ and depend on the substituents on the vinylidene ligand and the coordination environment at the metal center. More recent examples include ruthenium complexes of the tripodal $\mathrm{CH}_{3} \mathrm{C}\left(\eta^{5}-\mathrm{C}_{5} \mathrm{H}_{4}\right)\left(\mathrm{CH}_{2} \mathrm{PPh}_{2}\right)_{2}$ ligand, which coordin- ates the metal ion through its $\mathrm{Cp}$ ring and the two pendant phosphane side-arms $\left(\Delta G^{\circ} \approx 33 \mathrm{~kJ} / \mathrm{mol}\right.$ for secondary vinylidene ligands and $44 \mathrm{~kJ} / \mathrm{mol}$ for tertiary ones), ${ }^{[29]}$ the dinuclear bis(vinylidene) manganese complex $\left[\left(\eta^{5}\right.\right.$ $\left.\mathrm{C}_{5} \mathrm{H}_{4} \mathrm{Me}\right)(\mathrm{dmpe}) \mathrm{Mn}=\mathrm{C}=\mathrm{C}(\mathrm{Ph}) \mathrm{C}(\mathrm{Ph})=\mathrm{C}=\mathrm{Mn}(\mathrm{dmpe})\left(\eta^{5}-\right.$ $\left.\left.\mathrm{C}_{5} \mathrm{H}_{4} \mathrm{Me}\right)\right]^{2+}\left(\Delta G^{\neq}=56.7 \mathrm{~kJ} / \mathrm{mol}\right),{ }^{[30]}$ and the cycloheptatrienylmolybdenum complex $\left[\left(\eta^{7}-\mathrm{C}_{7} \mathrm{H}_{7}\right)(\right.$ dppe $) \mathrm{Mo}=\mathrm{C}=$ $\left.\mathrm{CH}_{2}\right]^{+}$(dppe $\left.=\mathrm{Ph}_{2} \mathrm{PC}_{2} \mathrm{H}_{4} \mathrm{PPh}_{2} ; \Delta G^{\neq}=51.9 \mathrm{~kJ} / \mathrm{mol}\right){ }^{[31]}$ The highest activation energy for vinylidene rotation of which we are aware has been observed for the rhenium complexes $\left[\left(\eta^{5}-\mathrm{C}_{5} \mathrm{H}_{5}\right)(\mathrm{NO})\left(\mathrm{PPh}_{3}\right) \mathrm{Re}=\mathrm{C}=\mathrm{CPhMe}^{+}\right.$and $\left[\left(\eta^{5}\right.\right.$ $\left.\left.\mathrm{C}_{5} \mathrm{H}_{5}\right)(\mathrm{NO})\left(\mathrm{PPh}_{3}\right) \mathrm{Re}=\mathrm{C}=\mathrm{CH}_{2}\right]^{+}\left(\Delta G^{\neq}=77.9 \mathrm{~kJ} / \mathrm{mol}\right) \cdot{ }^{[32]}$ The butyl/methyl-substituted vinylidene complex $\left[\left(\eta^{7}-\right.\right.$ $\left.\mathrm{C}_{7} \mathrm{H}_{7}\right)($ dppe $\left.) \mathrm{Mo}=\mathrm{C}=\mathrm{C}\left(\mathrm{C}_{4} \mathrm{H}_{9}\right)\left(\mathrm{CH}_{3}\right)\right]^{+}$displays separate resonance signals for the two different rotamers at $348 \mathrm{~K}$. ${ }^{[31]}$ The rotational barriers are usually thought of as being more steric than electronic in origin. Calculations on (vinylidene)metal complexes indicate that the intrinsic (electronic) energy difference between the vertical and horizontal rotamers amounts to no more than $10-20 \mathrm{~kJ} / \mathrm{mol} .{ }^{[25,33]}$ The energy barrier interconnecting them is thus expected to be fairly low. In view of the further remoteness of the terminal methylene group from the metal-ligand array it is therefore not surprising that allenylidene complexes present even lower rotational barriers than their vinylidene counterparts, and so the observation of a truly significant rotational barrier in an allenylidene ligand is quite unusual. This prompted us to study the dynamic behavior of $3 \mathbf{a}$ in 1,2$\mathrm{D}_{2} \mathrm{C}_{2} \mathrm{Cl}_{4}$ solution by ${ }^{31} \mathrm{P}$ NMR spectroscopy. Upon warming there was a very slight shift of the two singlet resonance signals, but no broadening was observed up to $388 \mathrm{~K}$, at which point 3a decomposed.

The sterically less hindered complex $\mathbf{3 b}$ exhibits one sharp singlet in its room-temperature ${ }^{31} \mathrm{P}$ NMR spectrum. 
When a solution in $\mathrm{CD}_{2} \mathrm{Cl}_{2}$ is cooled, this signal starts to broaden at $258 \mathrm{~K}$. At $233 \mathrm{~K}$, splitting into two equally intense, broad signals is observed, and at even lower temperatures the four resonance lines of a well-resolved $\mathrm{AB}$ spectrum are seen. The coupling constant $-30.65 \mathrm{~Hz}$ at $213 \mathrm{~K}$ - is typical of cis-disposed phosphane ligands (Figure 4). These findings would place the free energy of activation for rotation of the allenylidene ligand at $47 \mathrm{~kJ} / \mathrm{mol}$ at the coalescence temperature of $238 \mathrm{~K}$. They also indicate a horizontal orientation of the allenylidene ligand with the substituents on the terminal carbon atom orthogonal to the symmetry plane of the $\left[\mathrm{TpRuL}_{2}\right]$ moiety. This is in sharp contrast to the vertical arrangement proposed for the bi$s$ (triphenylphosphane)-substituted counterpart 3a. In the absence of X-ray data we can only speculate that in the vertical orientation the substituents on the terminal carbon atom would each approach the ferrocenyl backbone of the dppf ligand such that the horizontal orientation would be preferred on steric grounds (see Scheme 3).

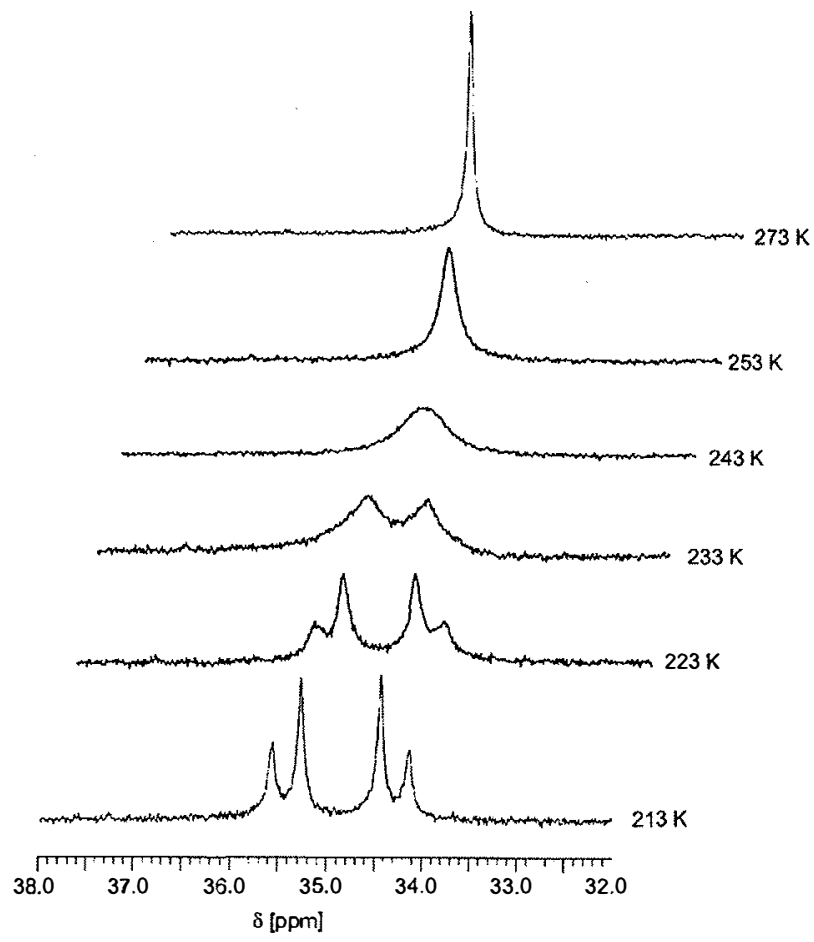

Figure 4. Dynamic ${ }^{31} \mathrm{P}$ NMR spectroscopy of compound $3 \mathbf{b}$ in $\mathrm{CD}_{2} \mathrm{Cl}_{2}$ solution

In the visible range the electronic spectra of the intensely colored complexes $\mathbf{2} \mathbf{a}$ and $\mathbf{3 a}$ are each dominated by $\mathbf{a}$ strong absorption band, at 527 (2a) or $522 \mathrm{~nm}$ (2b) in $\mathrm{CH}_{2} \mathrm{Cl}_{2}$ solution. This band is only very slightly solvatochromic, shifting to somewhat higher energies in the more polar solvent $\mathrm{CH}_{3} \mathrm{CN}$. For related allenylidene complexes of the trans-[Cl( $\left.\left(\mathrm{L}_{2}\right)_{2} \mathrm{Ru}\right]$ moiety, this absorption band has been assigned to an allowed transition from the metalbased second highest molecular orbital HOMO-1 to the LUMO, which is delocalized over the allenylidene ligand. This accounts for the strong Metal-to-Ligand Charge-
Transfer (MLCT) character of this band. ${ }^{[4]}$ This assignment also seems to be valid here, since a much weaker absorption at considerably lower energies $(907 \mathrm{~nm}$ in $2 \mathrm{a}$ and at $902 \mathrm{~nm}$ in $\mathbf{2 b}$ ) was observed for the forbidden HOMO $\rightarrow$ LUMO transition. With reference to the trans- $\left[\mathrm{Cl}(\mathrm{dppm})_{2} \mathrm{Ru}\right]-\mathrm{de}-$ rived complexes, the HOMO should also be dominated by the metal unit and have appreciable MLCT character as well. As found for the HOMO-1 $\rightarrow$ LUMO transition, it exhibits negative solvatochromism of a magnitude comparable to that of the main absorption band. We note that replacement of the trans-[Cl( $\left.\left(\mathrm{L}_{2}\right)_{2} \mathrm{Ru}\right]$ moiety by $\left[\mathrm{TpRuL}_{2}\right]$ apparently results in a somewhat smaller energy gap between the two highest occupied levels and the LUMO. This is inferred by comparison of the data for $\mathbf{2 a}$ and $\mathbf{2 b}$ with those for the related complex trans- $\left[\mathrm{Cl}(\mathrm{dppm})_{2} \mathrm{Ru}=\mathrm{C}=\mathrm{C}=\right.$ $\left.\mathrm{CPh}_{2}\right]^{+}$, which has its absorption maxima at 506 and $817 \mathrm{~nm}$. The data also point to a slightly larger energy gap between the two highest occupied levels for the $\left[\mathrm{TpRuL}_{2}\right]-$ derived complexes. The energy difference between the HOMO- $\rightarrow$ LUMO and the HOMO $\rightarrow$ LUMO transitions thus amounts to $1.01 \mathrm{eV}$ for $\mathbf{2 a}$ and $0.98 \mathrm{eV}$ for $\mathbf{2} \mathbf{b}$, as compared to $0.93 \mathrm{eV}$ for trans $-\left[\mathrm{Cl}(\mathrm{dppm})_{2} \mathrm{Ru}=\mathrm{C}=\mathrm{C}=\mathrm{CPh}_{2}\right]^{+}$.

In the ferrocenyl-substituted complexes $\mathbf{3 a}$ and $\mathbf{3 b}$ the intense HOMO-1 $\rightarrow$ LUMO transition band is shifted to somewhat lower energies, as in the diphenyl-substituted analogues $\left(\lambda_{\max }=538 \mathrm{~nm}\right.$ for $3 \mathbf{a}, 540 \mathrm{~nm}$ for $3 \mathbf{b}$, see Table 3). At even lower energies another very intense, broad band is found at $723(3 \mathrm{a})$ and $713(3 \mathrm{~b}) \mathrm{nm}$, tailing far into the near IR region and burying the HOMO $\rightarrow$ LUMO band. Again, a slight negative solvatochromism is noted when spectra in $\mathrm{CH}_{2} \mathrm{Cl}_{2}$ and $\mathrm{CH}_{3} \mathrm{CN}$ are compared. This band has no counterpart in $\mathbf{2} \mathbf{a}$ and $\mathbf{2} \mathbf{b}$ and is consequently attributed to a ferrocenyl-to-ligand MLCT charge transfer absorption. If the ferrocenyl substituent and the cumulenic carbon atoms are regarded as belonging to the same chromophore, this band may also be termed an Intraligand Charge Tranfer (ILCT) band, the charge density being shifted between two different sites within the same basic ligand. Irrespective of the exact interpretation, the presence of this additional band points to effective conjugation between the ferrocenyl substituent and the allenylidene chromophore. As discussed later, the above assignment is strongly supported by our results from UV/Vis spectroelectrochemical investigations on the ferrocenyl-based one-electron oxidation.

Spectra of the dppf-substituted complexes $\mathbf{2} \mathbf{b}$ and $\mathbf{3 b}$ are compared in Figure 5. The ferrocene-based absorption of the dppf ligand could not be located, since it is obscured by the much more intense, broad HOMO-1 $\rightarrow$ LUMO transition. All complexes presented here display another intense band at $350-356 \mathrm{~nm}(\log \varepsilon \approx 4)$. This feature seems to be characteristic of aryl-substituted allenylidene complexes and so is tentatively assigned to ILCT excitation from the arene substituent(s) to the metallacumulene chromophore. Absorptions at even higher energies in the UV region arise from the $n \rightarrow \pi^{*}$ and $\pi \rightarrow \pi^{*}$ transitions of the aryl-substituted phosphane ligands. ${ }^{[34]}$ 


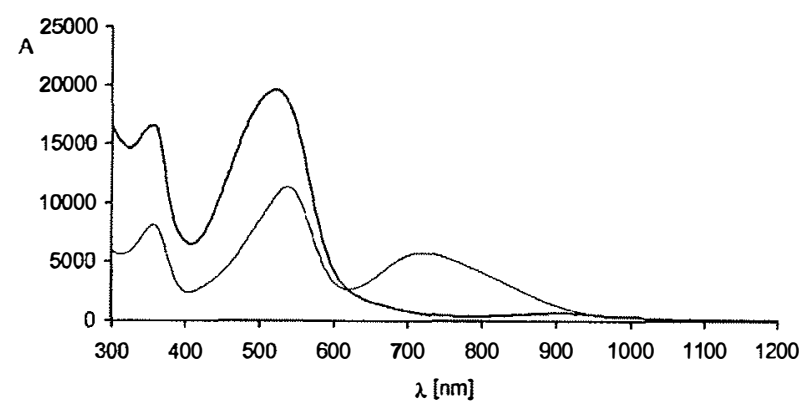

Figure 5. Optical spectra of complexes $\mathbf{2 b}$ and $\mathbf{3 b}$ in $\mathrm{CH}_{2} \mathrm{Cl}_{2}$

\section{Electrochemistry}

Electrochemical studies on the allenylidene complexes trans $-\left[\mathrm{Cl}(\mathrm{L})_{2} \mathrm{Ru}=\mathrm{C}=\mathrm{C}=\mathrm{C}\left(\mathrm{ER}_{n}\right)\left(\mathrm{R}^{\prime}\right)\right]^{+}$have shown that each of these complexes undergoes a one-electron oxidation and a one-electron reduction. ${ }^{[1,4]}$ By combining electrochemical and spectroscopic methods we have been able to characterize the oxidation as a primarily metal-based process (i.e., the $\mathrm{Ru}^{\mathrm{TI} / \mathrm{II}}$ couple) and the reduction as ligandbased, the latter assignment being confirmed by EPR and IR spectroscopy on their reduced forms. The reduction of the diphenyl-substituted complex trans $-\left[\mathrm{Cl}(\mathrm{dppe}){ }_{2} \mathrm{Ru}=\mathrm{C}=\right.$ $\left.\mathrm{C}=\mathrm{CPh}_{2}\right]^{+}$(4), related to $2 \mathrm{a}$, has meanwhile been investigated by Touchard and co-workers. These authors arrived at essentially the same conclusions and also corroborated the reduction site by exploring the chemical reactivity of the corresponding neutral radical. ${ }^{[35]}$ In that particular compound, a second, irreversible one-electron reduction was observed at a potential $-1.10 \mathrm{~V}$ lower than the first reversible reduction process. The $\mathrm{PPh}_{3}$-substituted diphenylallenylidene complex 2a exhibits essentially identical electrochemical behavior (Figure 6, bottom trace). The one-electron oxidation appears to be only partially reversible under ambient conditions but a meaningful analysis of the degree of chemical reversibility is precluded by its proximity to the anodic discharge limit of the electrolyte solution. Cooling to $-78{ }^{\circ} \mathrm{C}$ renders the voltammetric wave chemically revers-

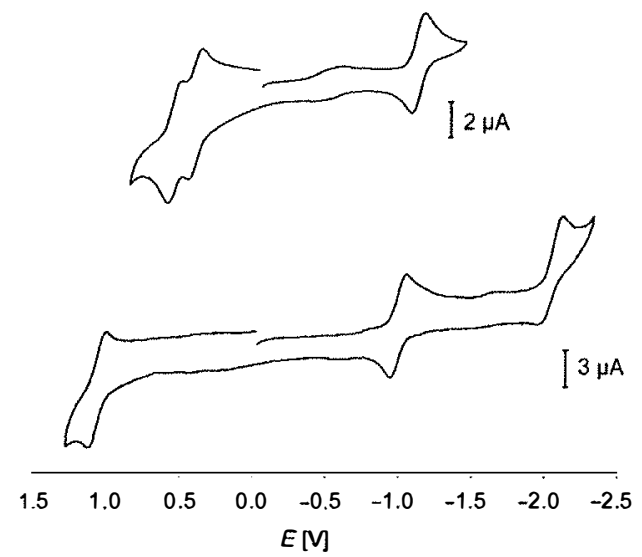

Figure 6. Cyclic voltammograms of complexes $2 \mathrm{a}\left(\mathrm{CH}_{2} \mathrm{Cl}_{2}, 215 \mathrm{~K}\right.$, $v=0.1 \mathrm{~V} / \mathrm{s}$, bottom trace) and $\mathbf{3 b}\left(\mathrm{CH}_{2} \mathrm{Cl}_{2}, 298 \mathrm{~K}, v=0.1 \mathrm{~V} / \mathrm{s}\right.$, top trace) ible even at low sweep rates and allowed us to determine its half-wave potential as $+1.05 \mathrm{~V}$ against the internal ferrocene/ferrocenium standard (Table 4). As with the dppmsubstituted complex 4 , two consecutive one-electron reductions are observed. While the first reduction at $E_{1 / 2}=$ $-1.00 \mathrm{~V}$ is chemically reversible under ambient conditions, the second reduction is not, and requires cooling to allow detection of the associated anodic return peak. Even so, only partial chemical reversibility could be achieved. It was, however, still possible to determine the half-wave potential of this redox couple as $-2.05 \mathrm{~V}$. We note that these potentials are very similar to those of trans $-\left[\mathrm{Cl}(\mathrm{dppe}){ }_{2} \mathrm{Ru}=\mathrm{C}=\right.$ $\left.\mathrm{C}=\mathrm{CPh}_{2}\right]^{+}{ }^{[35]}$ This further corroborates our previous finding that - given the same allenylidene ligand - the reduction potentials are virtually independent of the electron density on the metal, a further indication of the ligand-centered nature of this process. ${ }^{[4]}$

The analogous compound $\mathbf{2 b}$ contains an electroactive dppf ligand, which would be expected to oxidize at considerably lower potential than the $\mathrm{L}_{n} \mathrm{Ru}^{\mathrm{II}}$ entity. Thus, $\mathbf{2} \mathbf{b}$ displays a reversible one-electron wave at $+0.485 \mathrm{~V}$, more than $550 \mathrm{mV}$ more negative than the $\mathrm{Ru}^{\mathrm{II} / \mathrm{II}}$ couple of the $\mathrm{PPh}_{3}$ substituted congener $\mathbf{2 a}$. No further anodic processes could be observed within the accessible potential window. During our studies on the ferrocenylethyl-substituted aminoallenylidene complex trans- $\left[\mathrm{Cl}(\mathrm{dppm})_{2} \mathrm{Ru}=\mathrm{C}=\mathrm{C}=\mathrm{C}\left(\mathrm{NMe}_{2}\right)\right.$ $\left.\left(\mathrm{C}_{2} \mathrm{H}_{4} \mathrm{Fc}\right)\right]^{+}$we noticed that the $\mathrm{Ru}^{\mathrm{II} / \mathrm{III}}$ couple is shifted anodically by ca. $60 \mathrm{mV}$ relative to closely related complexes upon oxidation of the electroactive ferrocenyl moiety. ${ }^{[12]}$ In that particular example, the observed shift largely reflects the increased electrostatic repulsion between the positively charged centers. A much larger effect is to be expected in $\mathbf{2 b}$, in which the electroactive ferrocenyl moiety is directly linked to the metal ion. Given the proximity of the $\mathrm{Ru}^{\mathrm{II} / \mathrm{III}}$ process to the anodic discharge limit of the solvent in complex $\mathbf{2 a}$, it is thus not surprising that it lies outside the accessible potential range in the case of $\mathbf{2 b}$. The first reduction of this complex is again a fully reversible one-electron process, occurring at almost the same potential as in $2 \mathbf{a}(-1.01$ V), but no further reduction was observed in this solvent. Complex 3a has the electroactive ferrocenyl substituent attached to the terminal carbon atom of the allenylidene ligand and gives rise to a reversible one-electron wave at $E_{\mathrm{I} / 2}=+0.36 \mathrm{~V}$. As was the case for $2 \mathrm{a}$, the ruthenium-based oxidation is again shifted outside the potential window of the electrolyte solution. While this precludes us from quantifying the potential shift of the $\mathrm{Ru}^{\mathrm{II} / \mathrm{III}}$ couple induced by ferrocene oxidation, it nevertheless provides further evidence for effective

stituent and the cumulenic system, as already inferred from the optical data. Complexes $2 \mathbf{a}$ and $3 \mathbf{a}$ also offer the opportunity to assess the effect on the reduction potentials of replacement of a phenyl by a more strongly donating ferrocene substituent on the terminal carbon atom of the allenylidene ligand. Given the allenylidene-centered nature of the reduction processes, one would expect a cathodic shift of the $(+/ 0)$ and the $(0 /-)$ couples. This is indeed the case. The two reductions for $3 \mathrm{a}$ are observed at potentials 160 
Table 4. Electrochemical data for complexes $\mathbf{2 a - 3 b}$

\begin{tabular}{|c|c|c|c|c|c|c|}
\hline Complex & Solvent & $E_{1 / 2}\left[{ }^{[\mathrm{a}]}\left[\mathrm{Ru}^{\mathrm{II} / \mathrm{III}}\right]\right.$ & $E_{1 / 2}(\mathrm{dppf})^{[\mathrm{a}]}$ & $E_{1 / 2}\left(\mathrm{Fc} / \mathrm{Fc}^{+}\right)^{[\mathrm{a}]}$ & $E_{1 / 2}(+/ 0)^{[\mathrm{a}]}$ & $E_{1 / 2}(0 /-)^{[\mathrm{a}]}$ \\
\hline $2 a$ & $\begin{array}{l}\mathrm{CH}_{2} \mathrm{Cl}_{2} \\
\text { DMF }\end{array}$ & $\begin{array}{l}+1.05(158) \\
\text { n. d. }\end{array}$ & $\begin{array}{l}\text { n. a. } \\
\text { n. d. }\end{array}$ & $\begin{array}{l}\text { n. a. } \\
\text { n. a. }\end{array}$ & $\begin{array}{l}-1.00(138) \\
-0.83(78)\end{array}$ & $\begin{array}{l}-2.05(192) \\
-2.02^{\text {(b] }}\end{array}$ \\
\hline $2 b$ & $\begin{array}{l}\mathrm{CH}_{2} \mathrm{Cl}_{2} \\
\text { DMF }\end{array}$ & $\begin{array}{l}\text { n. d. } \\
\text { n. d. }\end{array}$ & $\begin{array}{l}+0.485(142) \\
\text { n. d. }\end{array}$ & $\begin{array}{l}\text { n. a. } \\
\text { n. a. }\end{array}$ & $\begin{array}{l}-1.01(134) \\
-0.83(72)\end{array}$ & $\begin{array}{l}\text { n. d. } \\
-2.00^{(b)}\end{array}$ \\
\hline $3 a$ & $\begin{array}{l}\mathrm{CH}_{2} \mathrm{Cl}_{2} \\
\mathrm{DMF}\end{array}$ & $\begin{array}{l}\text { n. d. } \\
\text { n. d. }\end{array}$ & $\begin{array}{l}\text { n. a. } \\
\text { n. a. }\end{array}$ & $\begin{array}{l}+0.36(138) \\
\text { n. d. }\end{array}$ & $\begin{array}{l}-1.16(146) \\
-0.99(80)\end{array}$ & $\begin{array}{l}-2.375^{[\mathrm{b}]} \\
-2.16^{[\mathrm{b}]}\end{array}$ \\
\hline $3 \mathbf{b}$ & $\begin{array}{l}\mathrm{CH}_{2} \mathrm{Cl}_{2} \\
\mathrm{DMF}\end{array}$ & $\begin{array}{l}\text { n. d. } \\
\text { n. d. }\end{array}$ & $\begin{array}{l}+0.51(144) \\
\text { n. d. }\end{array}$ & $\begin{array}{l}+0.37(142) \\
\text { n. d. }\end{array}$ & $\begin{array}{l}-1.165(136) \\
-1.00(78)\end{array}$ & $\begin{array}{l}\text { n. d. } \\
-2.13^{[b]}\end{array}$ \\
\hline
\end{tabular}

[a] $E_{1 / 2}$ values (in $\mathrm{V}$ ) are calibrated against the internal $\mathrm{Fc} / \mathrm{Fc}^{+}$standard, $\Delta E_{\mathrm{p}}$ values (in $\mathrm{mV}$ ) are given in brackets. [b] Peak potential of an irreversible process. $n$. d. = not detected; $n$. a. $=$ not applicable.

and ca. $320 \mathrm{mV}$ more negative than in its congener 2a. Despite all efforts, no return peak for the second reduction of 3a was observed. The reported shift of the $(0 /-)$ potential is therefore based on the respective positions of the forward peaks and provides only a qualitative measure. ${ }^{[36]}$

Lastly, complex $\mathbf{3 b}$ contains both secondary redox sites employed in this study, the dppf ligand on the metal and the ferrocenyl substituent on the terminal carbon atom $\mathrm{C}$ $\gamma$. Consequently, two reversible one-electron waves at potentials considerably more negative than those of the $\mathrm{Ru}^{\mathrm{II} / \mathrm{III}}$ couple of 2a are observed in the cyclic voltammogram of this complex (Figure 6, top trace). The half-wave potentials were determined as +0.37 and $+0.51 \mathrm{~V}$ relative to the ferrocene/ferrocenium standard. Comparisons with those of $\mathbf{2 b}$ and 3a argue for an assignment of the less anodic wave to the oxidation of the allenylidene-bound ferrocene moiety and the other one to that of the dppf ligand on the metal ion. Further evidence for this comes from spectroelectrochemical experiments, as detailed below. Paralleling the situation in compounds $\mathbf{2 a}$ and $\mathbf{3 a}$, the reversible reduction of 3b is shifted cathodically by $155 \mathrm{mV}$ relative to the diphenyl-substituted $\mathbf{2 b}$, which again reflects the higher electron density on the allenylidene ligand. No second reduction was observed for $3 \mathbf{b}$ in $\mathrm{CH}_{2} \mathrm{Cl}_{2} / \mathrm{Bu}_{4} \mathrm{NPF}_{6}$ solution. In order to assess the potential shifts induced on the second reduction by the presence of the ferrocenyl substituent, we also recorded voltammograms in $\mathrm{DMF} / \mathrm{Bu}_{4} \mathrm{NPF}_{6}$ solution. Thanks to its superior cathodic window we were now able to observe this process for all compounds, albeit as an irreversible event. The data in Table 5 show that in this solvent the effect

stituent is probably very similar for both reductions, although the irreversible nature of the second process only allows for a qualitative statement. ${ }^{[36]}$ No useful data, however, could be obtained for any of the oxidations in the DMF solvent.

The voltammetric data for all compounds under study are listed in Table 4. The peak potential splittings significantly exceed the predicted theoretical values of $59 \mathrm{mV}$ at $298 \mathrm{~K}$ and $39 \mathrm{mV}$ at $195 \mathrm{~K}^{\left[{ }^{[36]}\right.}$ This effect is largely due to uncompensated resistance of the electrolyte solution, as shown by the nearly identical peak-to-peak separations of the internal ferrocene standard, which is thought to represent an ideal Nernstian redox system, and the much less dis- torted responses in the more conducting $\mathrm{DMF} / \mathrm{NBu}_{4} \mathrm{PF}_{6}$ electrolyte.

\section{Spectroelectrochemistry}

\section{a) Oxidation}

We now address the question of how electron transfer from the secondary electroactive moieties attached either to the ruthenium or to the terminal carbon atom of the allenylidene ligand affects the spectroscopic properties of these complexes. As may be inferred from the above discussion, a combination of bulk electrolysis with infrared spectroscopy in an optically transparent thin-layer electrolysis (OTTLE) cell provides the most sensitive tool with which to examine bonding changes accompanying oxidation within the metallacumulene chromophore. The $\mathrm{PPh}_{3}$-ligated diphenylallenylidene complex $\mathbf{2 a}$ does not contain any additional redox-active moiety and thus serves as a benchmark system for elucidating the spectral changes concomitant with oxidation of the $[\{\mathrm{Ru}\}=\mathrm{C}=\mathrm{C}=\mathrm{C}(\mathrm{R})(\mathrm{Ph})]^{+}$system itself. It is thus discussed first.

Upon oxidation with IR monitoring, the strong $\mathrm{C}=\mathrm{C}=$ $\mathrm{C}$ stretch of the allenylidene ligand vanishes and is replaced by a weaker absorption at $1587 \mathrm{~cm}^{-1}$. This new band is best accommodated by the vinylidene resonance forms IV and $V$ (Scheme 4). Both place the unpaired spin on the internal carbon atom $C-\beta$ of the allenylidene ligand. At a first approximation, one may expect that the electron lost upon oxidation should originate from the HOMO orbital. According to recent DFT calculations on the parent cumulenylidene complexes of the $\mathrm{Cr}(\mathrm{CO})_{5}$ entity, ${ }^{[4,37]}$ and also our own work on the amino-substituted model complex trans$\left[\mathrm{Cl}\left(\mathrm{PH}_{3}\right)_{4} \mathrm{Ru}=\mathrm{C}=\mathrm{C}=\mathrm{C}\left\{\mathrm{N}\left(\mathrm{CH}_{3}\right)_{2}\right\}\left(\mathrm{CH}_{3}\right)\right]^{+}$, [4] this orbital is mainly composed of the ligand trans to the allenylidene ligand, the metal atom, and carbon atom $C-\beta$. Spin density calculations performed on trans $-\left[\mathrm{Cl}\left(\mathrm{PH}_{3}\right)_{4} \mathrm{Ru}=\mathrm{C}=\mathrm{C}=\right.$ $\left.\mathrm{C}\left(\mathrm{ER}_{n}\right)\left(\mathrm{CH}_{3}\right)\right]^{2+}\left[\mathrm{ER}_{n}=\mathrm{O}\left(\mathrm{CH}_{3}\right), \mathrm{S}\left(\mathrm{CH}_{3}\right), \mathrm{Se}\left(\mathrm{CH}_{3}\right), \mathrm{CH}_{3}\right]$ show that the orbital composition of the HOMO orbital faithfully translates into spin densities in the oxidized form. The mesomeric structures IV and $\mathbf{V}$ agree with these considerations.

Vinylidene complexes of ruthenium are characterized by a fairly intense IR band at around $1690-1580 \mathrm{~cm}^{-1} \cdot{ }^{[38]}$ The literature shows a clear trend toward lower energy absorp- 
Table 5. Spectroscopic data for complexes $\mathbf{2} \mathbf{a}-\mathbf{3 b}$ in different oxidation states

\begin{tabular}{|c|c|c|}
\hline Compound ${ }^{[a]}$ & $\begin{array}{l}\text { IR: } \\
\tilde{v}(B-H),(C=C) \text { or }(C=C=C)\left[\mathrm{cm}^{-1}\right]\end{array}$ & $\begin{array}{l}\text { UV/Vis: } \\
\lambda[\mathrm{nm}](\log \varepsilon)\end{array}$ \\
\hline 2a $\left[\mathrm{Ru}^{\mathrm{II}}\right]$ & $2489(\mathrm{w})(\mathrm{BH}), 1945(\mathrm{vs})$ & 354 (4.225), 525 (4.284), 909 (2.833) \\
\hline $2 \mathrm{a}^{+}\left[\mathrm{Ru}^{\mathrm{III}}\right]$ & $2521(\mathrm{w})(\mathrm{BH}), 1587(\mathrm{~s})$ & $411(4.282), 491$ (4.288), $830(3.200)$ \\
\hline $2 a^{-}$ & $2469(\mathrm{w}), 1969(\mathrm{~m}), 1959(\mathrm{~m})$ & $\begin{array}{l}350(4.342), 400(3.879), 480(3.865), 534(3.865) \text {, } \\
812(2.531)\end{array}$ \\
\hline 2b $\left[\mathrm{Fe}^{\mathrm{II}}(\mathrm{dppf}), \mathrm{Ru}^{\mathrm{II}}\right]$ & $2487(\mathrm{w}), 1939(\mathrm{vs}), 1573(\mathrm{~m}), 1588(\mathrm{~m})$ & $348(3.995), 361(\mathrm{sh}), 526(4.201), 901$ (2.852) \\
\hline $2 \mathbf{b}^{+}\left[\mathrm{Fe}^{\mathrm{III}}(\mathrm{dppf}), \mathrm{Ru}^{\mathrm{II}}\right]$ & 2513 (w), 1957 (vs), 1948 (vs) & 351 (4.060), $369(4.211), 530(4.044), 850(2.903)$ \\
\hline $2 \mathbf{b}^{2+}\left[\mathrm{Fe}^{\mathrm{IIT}}(\mathrm{dppf}), \mathrm{Ru}^{\mathrm{IIT}}\right]$ & not detected & $387(4.090), 513(3.949), 728(3.083)$ \\
\hline $2 \mathbf{b}^{-}$ & $2473(\mathrm{w}), 1966(\mathrm{~m}), 1956(\mathrm{~m})$ & $\begin{array}{l}351(4.156), 405(3.760), 452(3.680), 530(5.735), \\
630 \text { (sh, 3.057), } 847(2.813)\end{array}$ \\
\hline $3 \mathrm{a}\left[\mathrm{Fe}^{\mathrm{II}}(\mathrm{Fc}), \mathrm{Ru}^{\mathrm{II}}\right]$ & 2488 (w), 1948 (vs) & $356(3.903), 538(4.061), 723(3.756)$ \\
\hline $3 \mathrm{a}^{+}\left[\mathrm{Fe}^{\mathrm{III}}(\mathrm{Fc}), \mathrm{Ru}^{\mathrm{II}}\right]$ & 2506 (w), 1924 (s) & 298 (4.097), 353 (3.863), $544(4.000)$ \\
\hline $3 \mathrm{a}^{2+}\left[\mathrm{Fe}^{\mathrm{III}}(\mathrm{Fc}), \mathrm{Ru}^{\mathrm{III}}\right]$ & $2514(w), 1507(\mathrm{~s})$ & not detected \\
\hline $3 a^{-}-3$ & $2463(\mathrm{w}), 1969(\mathrm{~s})$ & 340 (3.929), $410(\mathrm{sh}), 451$ (3.813), 544 (3.744), 693 (2.653) \\
\hline 3b $\left[\mathrm{Fe}^{\mathrm{II}}(\mathrm{Fc}), \mathrm{Fe}^{\mathrm{II}}(\mathrm{dppf}), \mathrm{Ru}^{\mathrm{I}}\right]$ & $2488(w), 1945$ (vs) & $353(4.279), 538(4.290), 713(4.112)$ \\
\hline $3 b^{+}\left[\mathrm{Fe}^{\mathrm{III}}(\mathrm{Fc}), \mathrm{Fe}^{\mathrm{iI}}(\mathrm{dppf}), \mathrm{Ru}^{\mathrm{II}}\right]$ & $2506(\mathrm{w}), 1916(\mathrm{~m})$ & 353 (4.250), $540(4.228), 701$ (3.919) \\
\hline $3 b^{2+}\left[\mathrm{Fe}^{\mathrm{III}}(\mathrm{Fc}), \mathrm{Fe}^{\mathrm{III}}(\mathrm{dppf}), \mathrm{Ru}^{\mathrm{II}}\right]$ & $2488(\mathrm{w}), 1945(\mathrm{~s}), 1912(\mathrm{~m})$ & 315 (4.228), 353 (4.243), $475(\mathrm{sh}), 548$ (4.225), 685 (3.829) \\
\hline $3 b^{3+}\left[\mathrm{Fe}^{\mathrm{III}}(\mathrm{Fc}), \mathrm{Fe}^{\mathrm{III}}(\mathrm{dppf}), \mathrm{Ru}^{\mathrm{III}}\right]$ & $2519(w), 1524(s)$ & 368 (4.188), 468 (4.215), 557 (3.914), $702(4.047)$ \\
\hline $3 \mathbf{b}^{-}$ & $2470(w), 1963(\mathrm{~m})$ & $343(4.270), 413$ (3.941), $456(4.072), 549$ (4.005), 865 (2.771) \\
\hline
\end{tabular}

[a] All data in $\mathrm{C}_{2} \mathrm{H}_{4} \mathrm{Cl}_{2} / 0.25 \mathrm{M} \mathrm{Bu}_{4} \mathrm{NPF}_{6}$ at room temperature.

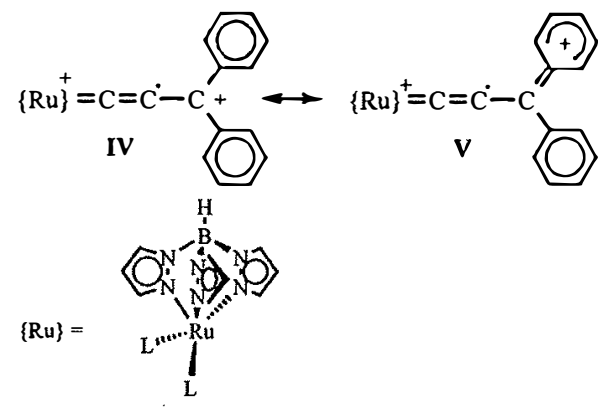

Scheme 4

tions for acceptor-substituted vinylidene ligands. This is demonstrated by the complexes $\left[\mathrm{Cp}\left(\mathrm{PPh}_{3}\right)_{2} \mathrm{Ru}=\mathrm{C}=\right.$ $\mathrm{C}(\mathrm{Ph})(\mathrm{R})]^{+\cdot}\left[\tilde{v}(\mathrm{C}=\mathrm{C})=1675 \mathrm{~cm}^{-1}\right.$ for $\mathrm{R}=\mathrm{C}_{7} \mathrm{H}_{7}, 1655$ $\mathrm{cm}^{-1}$ for $\mathrm{R}=\mathrm{CH}_{2} \mathrm{Ph}, 1638 \mathrm{~cm}^{-1}$ for $\mathrm{R}=\mathrm{I}$ or $\mathrm{Br}$, and $1585 \mathrm{~cm}^{-1}$ for $\left.\mathrm{R}=\mathrm{NNPh}\right) .^{[39-42]}$ The IR band observed for the oxidized form of complex $2 \mathbf{a}$ is at the low-energy border of this regime. In contrast to all other (vinylidene)ruthenium complexes so far reported it has the metal atom in a formal + III oxidation state, which may account for its fairly low energy. In any case, it is clear that ruthenium oxidation induces major bonding changes within the metallacumulene chromophore.

In complex 3a, oxidation involves the ferrocenyl moiety at the terminal carbon atom of the allenylidene ligand. This allows us to examine the effect of decreased electron density at this site on the position of the IR band directly. As shown

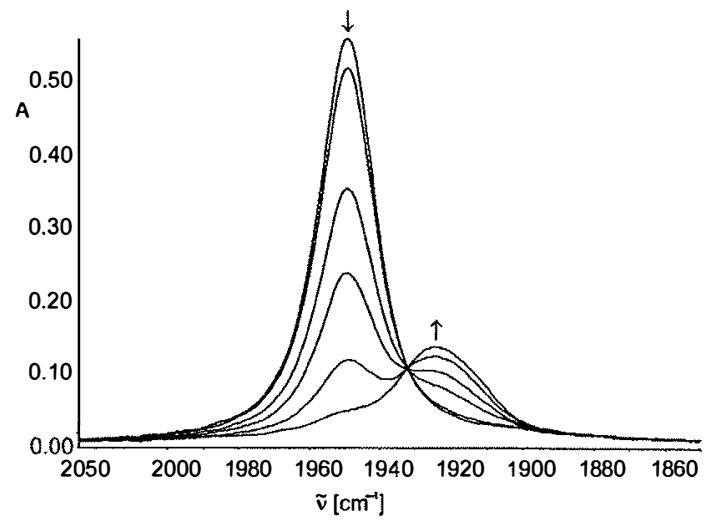

Figure 7. IR spectroelectrochemistry of complex $3 \mathrm{a}\left(1,2-\mathrm{Cl}_{2} \mathrm{C}_{2} \mathrm{H}_{4}\right.$ $298 \mathrm{~K}$ ); oxidation of the ferrocenyl substituent attached to the allenylidene ligand

in Figure 7, electrolysis at a potential positive to the anodic wave of the ferrocenyl substituent induces a red shift of the allenylidene band by ca. $20 \mathrm{~cm}^{-1}$ to a value of $1924 \mathrm{~cm}^{-1}$, together with an appreciable decrease in absorptivity. Subsequent reduction restores the original spectrum in nearly quantitative optical yield, showing that the smaller absorptivity is not an artifact of partial decomposition. In the dipositive, monooxidized form, the unsaturated $\mathrm{C}_{3}$ ligand bridges two positively charged entities. This should reduce the change in dipole moment during this vibration and decrease the absorptivity of this band. The same reasoning has been employed in explaining the considerably lower intensity of the allenylidene stretch in neutral allenylidene complexes as opposed to cationic ones, a situation qualitatively equivalent to the case here. ${ }^{[43]}$ 
The dppf-substituted complex $\mathbf{2} \mathbf{b}$ has its additional electroactive moiety at exactly the opposite end of the metallacumulene chromophore. It provides a study case for the effect on the position of the IR band of diminished electron density on the metal. Here, oxidation results in the disappearance of the original IR band and the simultaneous growth of a pair of closely spaced, equally intense bands at 1957 and $1948 \mathrm{~cm}^{-1}$, a blue shift relative to the $\mathrm{Ru}^{\mathrm{II}} / \mathrm{Fe}^{\mathrm{II}}$ precursor of an average of $15 \mathrm{~cm}^{-1}$ (Figure 8 ). The observation of a pair of bands instead of just one is most probably the result of Fermi coupling of the asymmetric $\mathrm{C}=\mathrm{C}=\mathrm{C}$ valence stretch with an overtone or a combination mode of other vibrational mode(s) of closely related energies. Although too weak to be detected by themselves, they gain intensity through coupling to the intense $\mathrm{C}=\mathrm{C}=\mathrm{C}$ stretch of the unsaturated ligand, which then causes the additional band. Similar observations have been made for the reduced forms of complexes $\mathbf{2 a}$ and $\mathbf{2 b}$ (vide infra). Notably, such apparent splitting of the valence stretch is observed only in certain oxidation states. Generally speaking, Fermi coupling is only encountered when there is a good energy match between the two underlying fundamentals. It is reasonable to assume that electron transfer alters the energy of at least one of the vibrational modes involved in this coupling, which would explain why such an effect may be observable in one oxidation state but not in another. Paul, Lapinte, and co-workers have very recently reported on such oxidation-state-dependent Fermi coupling between $\mathrm{C} \equiv \mathrm{C}$ and, presumably, $\mathrm{C}-\mathrm{C} \equiv \operatorname{modes}^{[44]}$ for alkynyl complexes $\left[\mathrm{Cp}{ }^{*}(\mathrm{dppe}) \mathrm{Fe}-\mathrm{C} \equiv \mathrm{C}-\mathrm{C}_{6} \mathrm{H}_{4} \mathrm{R}-4\right]^{n+}\left(n=0,1, \mathrm{Fe}^{\mathrm{II}, \mathrm{III}}\right) .^{[45,46]}$ Similar coupling between the $\mathrm{C} \equiv \mathrm{N}$ stretch and the $\mathrm{C} \equiv \mathrm{N}-\mathrm{C}$ bending modes of the isocyanide ligands in the triruthenium clusters $\left[\mathrm{Ru}_{3}(\mathrm{NCR})_{3}\left(\mu^{3}-\mathrm{O}\right)\left(\mu-\mathrm{CH}_{3} \mathrm{COO}\right)_{6}\right]^{n-}$ $(n=0,1)$ has recently been described by Kubiak et al. ${ }^{[47]}$ Since the band energy of the fundamental coupling with the $\mathrm{C}=\mathrm{C}=\mathrm{C}$ valence stretch is unknown, we adopt the center of the Fermi doublet as the energy of the unperturbed $\mathrm{C}=\mathrm{C}=\mathrm{C}$ stretch (and also of the other mode), but this is only an approximation. The alternative explanation of there being two distinct conformers with appreciably different $\tilde{v}(\mathrm{C}=\mathrm{C}=\mathrm{C})$ values cannot be discounted, but seems much

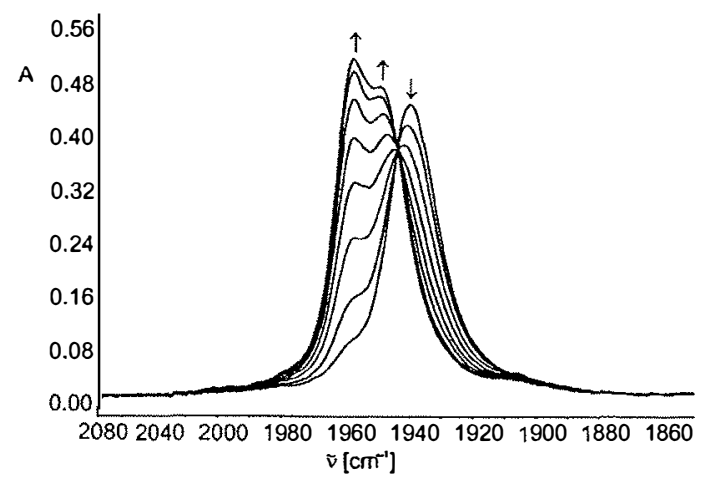

Figure 8. IR spectroelectrochemistry of complex $2 \mathbf{b}\left(1,2-\mathrm{Cl}_{2} \mathrm{C}_{2} \mathrm{H}_{4}\right.$, $298 \mathrm{~K})$; effect of oxidation of the ferrocene moiety of the dppf ligand

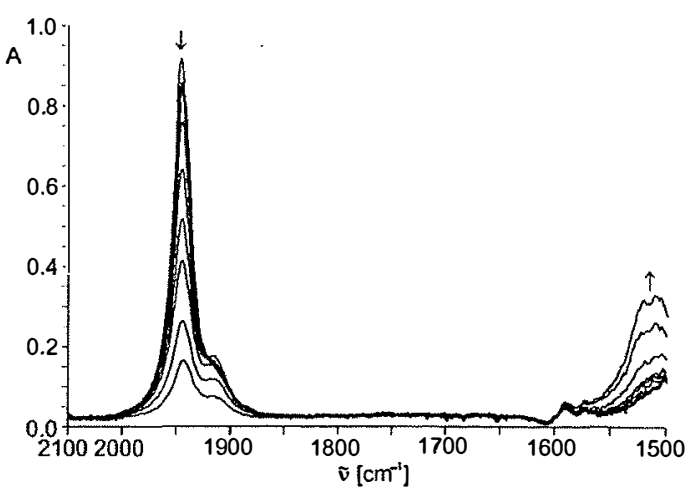

Figure 9. IR spectroelectrochemistry of complex $3 \mathbf{b}\left(1,2-\mathrm{Cl}_{2} \mathrm{C}_{2} \mathrm{H}_{4}\right.$, $298 \mathrm{~K}$ ); spectral changes concomitant with ruthenium oxidation

less likely. No splitting of this band is observed for complexes $\mathbf{3 a}$ or $\mathbf{3 b}$, in which such rotamers are known to exist and, from NMR spectroscopy (vide supra), not to interconvert on the IR timescale. We also note that oxidation at the [Tp(dppf)Ru] site results in a net increase of absorptivity. This can be explained well by the above reasoning, since the charge difference between the two sites bridged by the cumulenic chain, and hence the change in dipole moment associated with the asymmetric $\mathrm{C}=\mathrm{C}=\mathrm{C}$ stretch, is now enhanced.

Complex 3b, which features both types of secondary redox centers, constitutes the most demanding case under study, since it poses the question of which ferrocenyl entity is oxidized first. We have already pointed out that the measured redox potentials favor the first oxidation as involving the ferrocenyl substituent attached to the allenylidene ligand. IR spectroelectrochemistry provides compelling evidence for this assignment. During the first oxidation the $\mathrm{C}=\mathrm{C}=\mathrm{C}$ valence stretch at $1945 \mathrm{~cm}^{-1}$ is replaced by a significantly less intense absorption band at $1916 \mathrm{~cm}^{-1}$. The second oxidation occurs at the dppf ligand and shifts the IR band back to exactly its original position. This shows that - at least in terms of IR spectroscopy - the effects of one-electron oxidation of the electroactive moieties positioned at opposite ends of the allenylidene ligand exactly cancel each other. Both oxidized species display a high degree of chemical stability even on the longer timescales of spectroelectrochemical investigations. After bulk electrolysis following the first and second oxidation the starting material was recovered in ca. 95 and $92 \%$ optical yields, respectively.

Despite being obscured by the rising background current of the supporting electrolyte in cyclic voltammetry experiments, it still proved possible to examine the rutheniumcentered oxidation of complexes $\mathbf{3} \mathbf{a}$ and $\mathbf{3} \mathbf{b}$ under thin layer spectroelectrochemistry conditions. The results are very similar to those obtained for complex $2 \mathrm{a}$ : the IR bands in the region typical of the $\mathrm{C}=\mathrm{C}=\mathrm{C}$ stretch of the cumulenic ligand vanish and are replaced by new absorptions at 1507 $\left(3 \mathbf{a}^{2+}\right)$ or $1524 \mathrm{~cm}^{-1}\left(3 \mathbf{b}^{3+}\right)$, again pointing to a vinylidene structure (see Figure 9). We also note a significant red shift of the vinylidene band relative to the oxidized $\mathrm{Ru}^{\mathrm{III}}$ form 
of $2 \mathbf{a}$ as the electron density of these complexes decreases further.

Electrolysis under UV/Vis monitoring conditions revealed the effects on the optical spectra of complexes $\mathbf{2 b}$, $\mathbf{3 a}$, and $\mathbf{3 b}$ of electron transfer from the secondary redox sites. Spectral changes induced by oxidation of the dppf ligand in $\mathbf{2 b}$ are rather small, the most prominent effects ing a blue shift of the HOMO $\rightarrow$ LUMO band by $775 \mathrm{~cm}^{-1}$ and the development of a former shoulder at $361 \mathrm{~nm}$ into a distinct band located at $369 \mathrm{~nm}$, while the main absorption band at $526 \mathrm{~nm}$ remains virtually unchanged. The most likely explanation is provided by reference to our earlier work on amino-substituted allenylidene complexes of the trans $-\left[\mathrm{Cl}(\mathrm{dppm})_{2} \mathrm{Ru}\right]$ fragment. ${ }^{[48]}$ Here we found that the electron density on the phosphane ligands was quite small for both occupied frontier levels, and this may also hold for the mixed Tp/diphosphane complexes described here. Our experimental observations can then be accommodated by the assumption that the HOMO level has some contribution from the phosphane ligands while there is only a negligible one to the lower-lying HOMO-1 orbital. For complexes $3 \mathbf{a}$ and $\mathbf{3 b}$, oxidation of the ferrocene moiety would be expected to have a much more profound effect on the UV/Vis spectra, since the ferrocene moiety now constitutes an integral part of the chromophore. Bulk electrolysis of 3a at a potential more positive than the first anodic wave indeed causes a bleaching of the intense low-energy absorption band at $723 \mathrm{~nm}$ (Figure 10), this finding lending further support to our assignment of this band as resulting from charge transfer from the ferrocene donor to the allenylidene acceptor moieties within this chromophore. As the ferrocene moiety is oxidized, no such transition is possible any longer. Further changes are a slight red shift of the prominent absorption band by some $200 \mathrm{~cm}^{-1}$ and an absorptivity decrease of the third prominent feature near $355 \mathrm{~nm}$, accompanied by a slight shift to higher energies. The direction of the shift of the former band is as would be anticipated on the basis of our results on heteroatomsubstituted allenylidene complexes trans $-\left[\mathrm{Cl}(\mathrm{dppm})_{2} \mathrm{Ru}=\right.$ $\left.\mathrm{C}=\mathrm{C}=\mathrm{C}\left(\mathrm{ER}_{n}\right)\left(\mathrm{R}^{\prime}\right)\right]^{+}$, but its magnitude is again fairly small. Nearly identical observations were made during the first anodic step of compound $3 \mathbf{b}$, featuring both kinds of

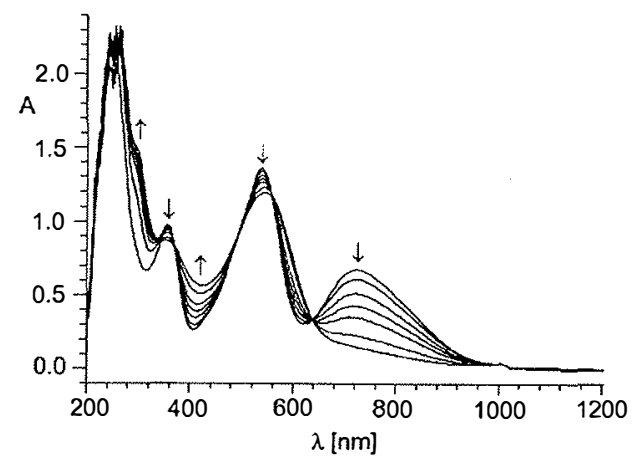

Figure 10. UV/Vis spectroelectrochemistry of complex 3a (1,2$\mathrm{Cl}_{2} \mathrm{C}_{2} \mathrm{H}_{4}, 298 \mathrm{~K}$ ); oxidation of the ferrocenyl substituent attached to the allenylidene ligand secondary redox centers (Table 5). This reconfirms our previous assignment that it is the ferrocene moiety at the allenylidene ligand that is oxidized first. The second oxidation of this compound causes only a slight blue shift of the lower energy band, along with a further decrease in absorptivity.

For complexes $\mathbf{2 a}, \mathbf{2 b}$, and $\mathbf{3 b}$ we were even able to monitor the spectral changes accompanying oxidation at the ruthenium center. For $\mathbf{2} \mathbf{a}$ and $\mathbf{2} \mathbf{b}$ the effects are very similar. As an example, Figure 11 displays the spectroscopic traces during the second oxidation of $\mathbf{2 b}$. The HOMO $\rightarrow$ LUMO and HOMO-1 $\rightarrow$ LUMO bands experience shifts to higher energies, by 1050 and $1300 \mathrm{~cm}^{-1}$ (2a) or $625 \mathrm{~cm}^{-1}$ for the HOMO-1 $\rightarrow$ LUMO transition in $\mathbf{2 b}$. In this latter compound there is no distinct band for the excitation from the HOMO level but only a broad absorption at ca. $700 \mathrm{~nm}$. As the oxidation proceeds, an intense band develops at $411 \mathrm{~nm}(2 \mathrm{a})$ or $351 \mathrm{~nm}(\mathbf{2 b})$. Since only one band in the $350-600-\mathrm{nm}$ region is observed for the $\mathrm{Ru}^{\mathrm{III}}$ forms of allenylidene complexes of the $\mathrm{ClRu}(\mathrm{dppm})_{2}$ entity, we assume that the additional band (probably the one at higher energy) arises from ligand-to-metal charge transfer from the $\mathrm{Tp}$ ligand to $\mathrm{Ru}^{\mathrm{III}}$. The fully oxidized form of complex $\mathbf{3 b}$ differs from the other two in that its spectrum, in terms of band positions, is surprisingly similar to that of the $\mathrm{Ru}^{\mathrm{II}} / \mathrm{Fe}^{\mathrm{II}}(\mathrm{Fc}) /$ $\mathrm{Fe}^{\mathrm{II}}(\mathrm{dpp})$ starting material. The intensities of the band near 700 and the one near $550 \mathrm{~nm}$, however, are just the opposite of what they were in the beginning, the band at lower energy now being very strong and the one at higher energy being rather weak. At present we have no plausible explanation for this pattern, but note that it seems to be associated with the ferrocenium moiety at the allenylidene ligand. This follows from comparison of the spectra of $\mathbf{2} \mathbf{b}^{2+}$ and $3 b^{3+}$. Another intense band at $468 \mathrm{~nm}$ may again arise from a LMCT transition from the Tp ligand to $\mathrm{Ru}^{\mathrm{III}}$.

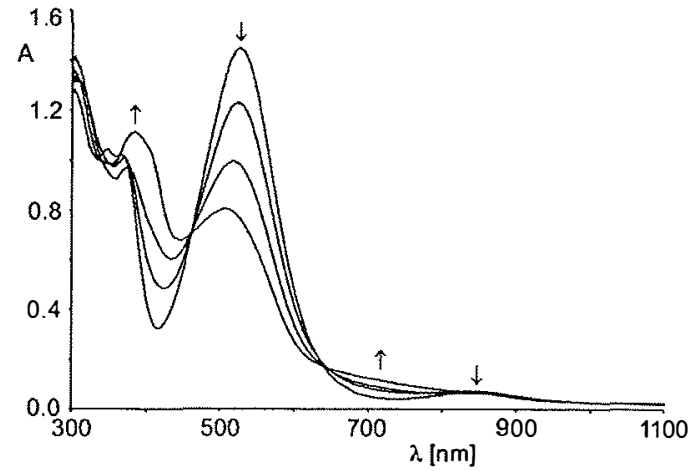

Figure 11. UV/Vis spectroelectrochemistry of complex 2b (1,2$\mathrm{Cl}_{2} \mathrm{C}_{2} \mathrm{H}_{4}, 298 \mathrm{~K}$ ); effect of oxidation of the ferrocene moiety of the dppf ligand

\section{b) Reduction}

It has already been mentioned that the reduction of allenylidene complexes mainly involves the allenylidene ligand. From the shift of the IR band upon reduction of the SR and $\mathrm{SeR}$ substituted complexes trans-[Cl(dppm $)_{2} \mathrm{Ru}=\mathrm{C}=$ $\left.\mathrm{C}=\mathrm{C}(\mathrm{ER})\left(\mathrm{R}^{\prime}\right)\right]^{+}$and the coupling pattern of the unpaired 
electron in their reduced forms, we have concluded that the unpaired spin mainly resides on the terminal carbon atom. ${ }^{[1,2]}$ Touchard and co-workers have recently presented convincing evidence that this is also true for the reduced form of the diphenyl-substituted trans-[Cl(dppe ${ }_{2} \mathrm{Ru}=\mathrm{C}=$ $\left.\mathrm{C}=\mathrm{CPh}_{2}\right]^{+}$, closely related to the complexes discussed here. ${ }^{[35]}$ DFT calculations on variously substituted model complexes trans $-\left[\mathrm{Cl}\left(\mathrm{PH}_{3}\right)_{4} \mathrm{Ru}=\mathrm{C}=\mathrm{C}=\mathrm{C}\left(\mathrm{ER}_{n}\right)\left(\mathrm{CH}_{3}\right)\right]^{\circ}$ $\left[\mathrm{ER}_{n}=\mathrm{N}\left(\mathrm{CH}_{3}\right)_{2}, \mathrm{O}\left(\mathrm{CH}_{3}\right), \mathrm{S}\left(\mathrm{CH}_{3}\right), \mathrm{Se}\left(\mathrm{CH}_{3}\right), \mathrm{CH}_{3}\right]$, which we will detail elsewhere, have broadly confirmed these conclusions but also indicate considerable spin density on the metal-bound carbon atom $\mathrm{C}-\alpha$. This in turn fully agrees with the orbital composition of the LUMO as established by quantum mechanical calculations ${ }^{[4,9-11,37]}$ and the well established regiochemistry of nucleophilic addition to the allenylidene ligand. ${ }^{[8,49]}$ The reversible nature of the first reduction for each of the complexes presented here provided us with the opportunity also to examine the spectral changes accompanying this process. Again, we expected the most revealing results to come from IR spectroelectrochemistry. Since none of the appended secondary redox sites can be reduced, the results are very similar for all complexes. Figure 12 displays the spectral traces recorded during the reduction of complex $\mathbf{2 b}$ as a representative example. In each case we observe a blue shift of the $\mathrm{C}=\mathrm{C}=\mathrm{C}$ band by some 20 wavenumbers, along with an appreciable decrease in intensity. We again confirmed that this was not caused by decomposition of the reduced species, back-electrolysis in each case restoring the original spectrum in optical yields of more than $95 \%$. We note that two IR bands spaced by ca. $10 \mathrm{~cm}^{-1}$ were observed for the reduced forms of complexes $\mathbf{2 a}$ and $\mathbf{2} \mathbf{b}$, while there was only one for complexes 3a and 3b. The average shift, however, is almost constant within the entire series and amounts to ca. $20 \mathrm{~cm}^{-1}$. While all the mesomeric structures depicted in Scheme 5 place the unpaired spin either on the carbon atom $C-\alpha$ or on $C-\gamma$, we note that VI accounts for the high-energy shift of the IR band. Relevant data are listed in Table 5.

In UV/Vis spectroelectrochemical experiments, reduction was observed to change the intensities of the original absorption bands rather than their positions. Representative examples are provided in Figures 13 and 14, while the cor-

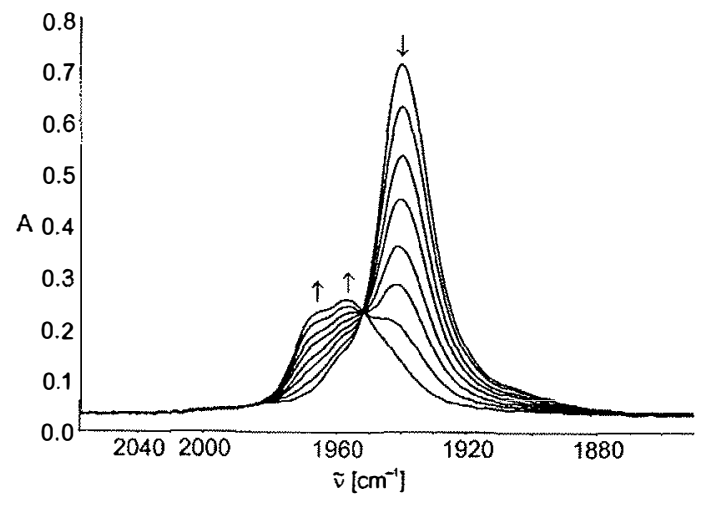

Figure 12. IR spectroelectrochemistry of complex $\mathbf{2 b}\left(1,2-\mathrm{Cl}_{2} \mathrm{C}_{2} \mathrm{H}_{4}\right.$, $298 \mathrm{~K})$; spectral changes accompanying reduction

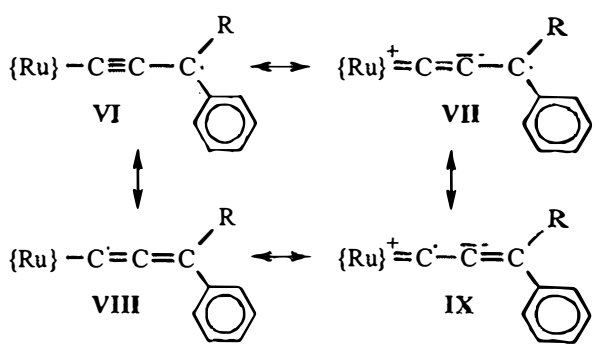

Scheme 5

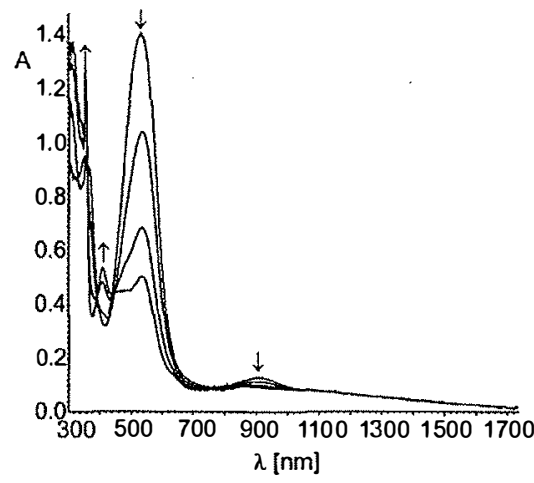

Figure 13. UV/Vis spectroelectrochemistry of complex $2 \mathbf{b}(1,2-$ $\mathrm{Cl}_{2} \mathrm{C}_{2} \mathrm{H}_{4}, 298 \mathrm{~K}$ ); spectral changes accompanying reduction

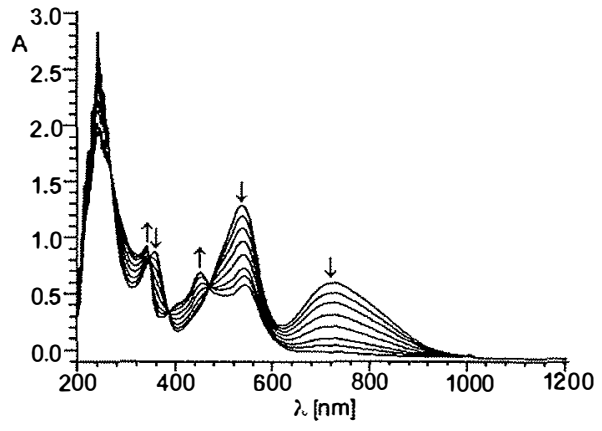

Figure 14. UV/Vis spectroelectrochemistry of complex 3a $(1,2-$ $\mathrm{Cl}_{2} \mathrm{C}_{2} \mathrm{H}_{4}, 298 \mathrm{~K}$ ); spectral changes accompanying reduction

responding data are listed in Table 5. This somewhat unexpected result points to a nearly parallel energy shift of all frontier orbitals involved in the electronic transitions upon reduction. The lower absorptivities may originate from partial loss of the charge-transfer character of these bands as the electron-accepting propensity of the allenylidene ligand is diminished. We note that the main absorption band originating from the HOMO-1 $\rightarrow$ LUMO transition seemingly splits into two individual bands, which remain unresolved for complex $\mathbf{2 b}$ but are clearly resolved for all other complexes, the energy difference increasing in the order $\mathbf{2 b}<$ $2 a<3 a \approx 3 b$. Another striking observation is the complete loss of the ferrocenyl-to-ligand (or intraligand) chargetransfer absorption for the ferrocenyl-substituted complexes $3 \mathbf{a}$ and $\mathbf{3 b}$, while a weak band identical to that seen for the HOMO $\rightarrow$ LUMO transition in the reduced forms of complexes $\mathbf{2} \mathbf{a}$ and $\mathbf{2} \mathbf{b}$ is now observed for $\mathbf{3 b}$ (Table 5). Des- 
pite their loss of intensity, the transition bands in the visible region are still quite strong and obscure the expected ferrocenyl-based absorptions. A new band at $400-410 \mathrm{~nm}$ was observed for all complexes and cannot conclusively be assigned at present. Another feature common to all reduced forms is an intense absorption at ca. $350 \mathrm{~nm}$. Bands of this type are familiar for aryl-substituted methyl radicals of the type $\mathrm{Ar}_{n} \mathrm{CR}_{3-n}$, which are characterized by sharp, intense absorptions at $325-360 \mathrm{~nm} \cdot{ }^{[50-53]}$ This argues for efficient incorporation of the aryl substituents into the $\mathrm{Ru}=\mathrm{C}=\mathrm{C}=$ $C(R)\left(R^{\prime}\right)$ chromophore and the relevance of resonance forms VI and VII, which both place the unpaired spin on the carbon atom adjacent to the aromatic rings.

More evidence for spin delocalization into the aromatic substituents was provided by EPR spectroscopy. The reduced forms of complexes $\mathbf{2} \mathbf{a}$ and $\mathbf{2} \mathbf{b}$, frozen in a $1,2-$ $\mathrm{Cl}_{2} \mathrm{C}_{2} \mathrm{H}_{4}$ glass at $4 \mathrm{~K}$, display slightly broadened isotropic signals at $g$-values typical of organic paramagnetic species (i.e., close to the free electron value of 2.0023; Table 6). For $\mathbf{3 a}$ and $\mathbf{3 b}$, however, the spectra were of the rhombic type, with small but clearly detectable $g$-value anisotropies indicating some transition metal contribution, most probably from the ${ }^{57} \mathrm{Fe}$ nucleus of the Fc substituent. Such coupling also prevails in liquid solution, as is evident from a satellite doublet with a signal splitting of $22.3 \mathrm{G}$ (Figure $15 ;{ }^{57} \mathrm{Fe}$ has a nuclear spin of $1 / 2$ and a natural abundance of $2.15 \%$ ). No further resolution of the EPR signal was obtained, however. This is in sharp contrast to observations made by Rigaut, Dixneuf, and co-workers and in our own laboratory on the reduced forms of allenylidene complexes bearing the trans $-\left[\mathrm{Cl}\left(\mathrm{L}_{2}\right)_{2} \mathrm{Ru}\right]$ fragment $\left(\mathrm{L}_{2}=\mathrm{dppm}\right.$, dppe). These display resolved couplings to the hydrogen atoms on the substituents bonded to the allenylidene ligand and the phosphane $\mathrm{P}$ atoms coordinated to the metal ion. ${ }^{[1-3,5]}$ In the mixed $\mathrm{Tp} /$ phosphane complexes described here, coupling to the arene protons, the two magnetically different sets of nitrogen atoms of the Tp ligand, and the phosphane $P$ atoms would therefore be expected. It is possible that the larger number of magnetically independent nuclei together with some participation by a metal atom give rise to strongly overlapping resonance lines that cannot be resolved. It is quite revealing to note that the resonance signals are significantly broadened relative to the analogous complexes of the trans- $\left[\mathrm{Cl}(\mathrm{dppm})_{2} \mathrm{Ru}\right]$ entity.

Table 6. EPR data for the reduced forms of complexes $\mathbf{2 a - 3 b}$

\begin{tabular}{lll}
\hline & $4 \mathrm{~K}$ & $298 \mathrm{~K}$ \\
& $g_{\text {iso }}$ or $g_{x x}, g_{y y,} g_{\mathrm{zz}}\left(g_{\mathrm{av}}\right)^{[\mathrm{a}]}$ & $g_{\text {iso }}\left(\mathrm{A}\left\{{ }^{57} \mathrm{Fe}\right\}\right)$ \\
\hline $2 \mathrm{a}$ & 2.0027 & $2.0018(-)$ \\
$2 \mathrm{~b}$ & 2.0027 & $2.0030(-)$ \\
$3 \mathrm{a}$ & $2.0228,2.0094,2.0011(2.0111)$ & $2.0108(22.3 \mathrm{G})$ \\
$3 \mathrm{~b}$ & $2.0215,2.0111,2.0016(2.0114)$ & $2.0110(22.3 \mathrm{G})$ \\
\hline [a] $g_{\mathrm{av}}=\left\{1 / 3\left(g_{\mathrm{xx}}{ }^{2}+g_{\mathrm{yy}}{ }^{2}+g_{\mathrm{zz}}{ }^{2}\right)\right\}^{1 / 2}$. &
\end{tabular}
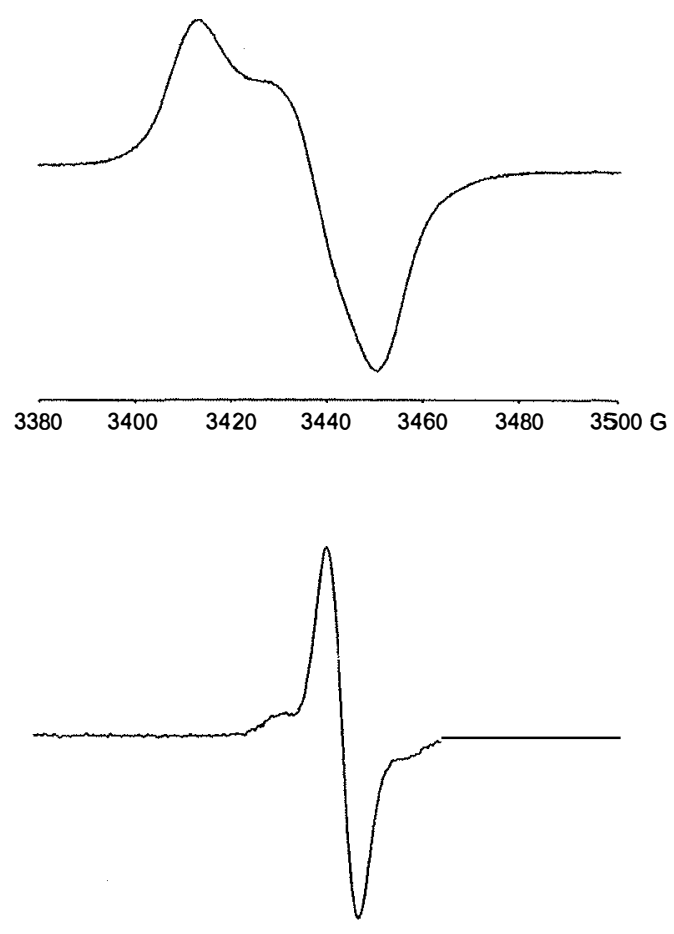

$\begin{array}{lllllll}3360 & 3380 & 3400 & 3420 & 3440 & 3460 & 3480 \mathrm{G}\end{array}$

Figure 15. EPR spectra of the reduced form of complex 3a in (a) a 1,2- $\mathrm{Cl}_{2} \mathrm{C}_{2} \mathrm{H}_{4}$ glass at $4 \mathrm{~K}$ (top trace) or (b) in $1,2-\mathrm{Cl}_{2} \mathrm{C}_{2} \mathrm{H}_{4}$ solution at $300 \mathrm{~K}$ (bottom trace)

\section{c) The IR Frequency of the B-H Stretch}

The position of the $\mathrm{B}-\mathrm{H}$ stretch in infrared spectra has been recognized as an indicator for the coordination mode of the $\mathrm{Tp}$ ligand (i.e., $\kappa^{3}$ versus $\kappa^{2}$ coordination). ${ }^{[54,55]}$ It has, however, only very recently been realized that the frequency of this band also corresponds to the electron density on the metal ion to which it is coordinated and, more specifically, to its oxidation state. Thus, O'Hare and co-workers have just published a series of mixed-sandwich complexes containing both the $\mathrm{Cp}$ and the Tp ligand or the 3,5-dimethyl derivative thereof, several of them in the adjacent $\mathrm{M}^{\mathrm{II}}$ and $\mathrm{M}^{\mathrm{III}}$ oxidation states $(\mathrm{M}=\mathrm{V}, \mathrm{Cr}, \mathrm{Co}, \mathrm{Ni}) \cdot{ }^{\left[{ }^{[5]} \text { In }\right.}$ all these cases oxidation of the metal atom was found to induce a shift of the $\mathrm{B}-\mathrm{H}$ band to higher energies, though of a strongly varying magnitude $\left(7-72 \mathrm{~cm}^{-1}\right)$. We have made the same observations with the complexes reported here. As the data for complexes $\mathbf{2 a}$ and $\mathbf{3 b}$ show (see Table 5), oxidation at the ruthenium atom increases the energy of the $\mathrm{B}-\mathrm{H}$ stretch by about $30 \mathrm{~cm}^{-1}$ while the decreasing electron density on the ruthenium atom by oxidation at the dppf ligand has a somewhat smaller effect of some $25 \mathrm{~cm}^{-1}(\mathbf{b})$. Ferrocene oxidation at the allenylidene ligand also shifts the $\mathrm{B}-\mathrm{H}$ band to higher energy (3a). Likewise, the reduced forms of these allenylidene complexes display their $\mathrm{B}-\mathrm{H}$ band at some $15-25 \mathrm{~cm}^{-1}$ lower energy, although this process mainly involves the organic ligand. Thus, variation of the $\mathrm{B}-\mathrm{H}$ stretch with the oxidation state 
of the metal atom or that of any redox-active ancillary ligand bonded to it seems to be a quite general result and we expect additional examples of such behavior as more redox pairs of this type are characterized.

\section{Conclusions}

We have investigated allenylidene complexes $\left[\mathrm{TpL}_{2} \mathrm{Ru}=\right.$ $\mathrm{C}=\mathrm{C}=\mathrm{C}(\mathrm{Ph})(\mathrm{R})]^{+}$. Substitution of dppf by less strongly donating $\mathrm{PPh}_{3}$ ligands or of the phenyl by a ferrocenyl substituent shifts the IR and electronic absorption bands to lower energies, in line with previous results on complexes based on the trans-[Cl(dppm $\left.)_{2} \mathrm{Ru}\right]$ moiety. Oxidation of ferrocene-based redox sites attached either to the metal atom $\left(\mathrm{L}_{2}=\mathrm{dppf} \mathbf{2} \mathbf{b}, \mathbf{3 b}\right)$ or to the allenylidene ligand $(\mathrm{R}=$ Fc: 3a and 3b) strongly attenuates these effects. The same holds for reduction, which mainly involves a ligand-centered, delocalized orbital. These studies also show that aromatic substituents at the allenylidene ligand are efficiently incorporated into the chromophoric system. Thus, the Fcsubstituted complexes $\mathbf{3 a}$ and $\mathbf{3 b}$ display an intense, lowenergy absorption band attributable to charge transfer from the ferrocenyl substituent to the allenylidene ligand. Oxidation of the Fc moiety and reduction both cause bleaching of this feature. EPR studies on the reduced forms of $3 a$ and $3 \mathrm{~b}$ reveal coupling of the unpaired spin with the ${ }^{57} \mathrm{Fe}$ nucleus of the ferrocenyl substituent. In their IR spectra some of the oxidized or reduced forms display an apparent splitting of the allenylidene band. This is interpreted in terms of Fermi coupling between the $\mathrm{C}=\mathrm{C}=\mathrm{C}$ fundamental and an overtone or combination of (an)other vibration(s).

Cyclic voltammetry studies reveal that both types of ferrocene-based redox systems are oxidized at much lower potential than the ruthenium center. Although the $\mathrm{Ru}^{\mathrm{II} / 1 \mathrm{II}}$ process lies outside the anodic window of the supporting electrolyte solution in voltammetric studies, it was still possible to perform this oxidation under thin layer conditions in an OTTLE cell. This latter oxidation induces more substantial bonding changes within the cumulenylidene system. Results from IR spectroelectrochemistry point to a vinylidene resonance structure for the $\mathrm{Ru}^{\mathrm{III}}$ forms of these complexes. The frequency of the $\mathrm{B}-\mathrm{H}$ stretch of the Tp ligand is also sensitive to the overall oxidation state of the molecule. Oxidation of any of the ferrocene entities or the ruthenium shifts this band to higher energies, while a red shift is observed upon reduction.

The unsymmetrically substituted allenylidene complexes $\left[\mathrm{TpL}_{2} \mathrm{Ru}=\mathrm{C}=\mathrm{C}=\mathrm{C}(\mathrm{Ph})(\mathrm{Fc})\right]^{+}$(3a and $\mathbf{3 b}$ ) are dynamic in solution, due to an energy barrier to rotation around the $\mathrm{Ru}=\mathrm{C}$ bond. Two isomeric forms differing in the relative positions of the $\mathrm{Fc}$ and the $\mathrm{Ph}$ substituents are discernible for the $\mathrm{PPh}_{3}$-substituted congener $3 \mathrm{a}$ up to $388 \mathrm{~K}$ in 1,2 $\mathrm{D}_{2} \mathrm{C}_{2} \mathrm{Cl}_{4}$, at which point this compound decomposes. The observation of just one singlet resonance for each isomer by ${ }^{31} \mathrm{P}$ NMR spectroscopy argues for a vertical orientation of the allenylidene ligand. This is in agreement with the crystallographically determined structures for $\mathbf{2} \mathbf{a}$ and $\mathbf{2 b}$, the latter presented here. ${ }^{[13]}$ For the dppf-substituted $\mathbf{3 b}$, however, splitting of the singlet ${ }^{31} \mathrm{P}$ NMR resonance into a well-resolved $\mathrm{AB}$ quadruplet is observed upon cooling in $\mathrm{CD}_{2} \mathrm{Cl}_{2}$, pointing to a horizontal alignment of the allenylidene ligand. The energy barrier for allenylidene rotation is determined as $47 \mathrm{~kJ} / \mathrm{mol}$ at the coalescence temperature of $238 \mathrm{~K}$.

\section{Experimental Section}

General: All manipulations were performed by standard Schlenk techniques under argon. $\mathrm{CH}_{2} \mathrm{Cl}_{2}$ and $1,2-\mathrm{Cl}_{2} \mathrm{C}_{2} \mathrm{H}_{4}$ were distilled from $\mathrm{CaH}_{2}$ and stored over molecular sieves $(4 \AA)$. All solvents were deoxygenated by at least three freeze-pump-thaw cycles and saturation with argon prior to use. Benzoylferrocene, $[\mathrm{Tp}(\mathrm{dppf}) \mathrm{RuCl}],\left[\mathrm{TpRu}\left(\mathrm{PPh}_{3}\right)_{2} \mathrm{Cl}\right]$, and $\left[\mathrm{TpL}_{2} \mathrm{Ru}=\mathrm{C}=\mathrm{C}=\mathrm{CPh}_{2}\right]^{+}$ $\left(\mathrm{L}_{2}=2 \mathrm{PPh}_{3}\right.$, dppf) were obtained by literature methods. ${ }^{[13,18,56,57]}$ Electrochemistry and spectroelectrochemistry were performed as described in an earlier publication. ${ }^{[4]}$ All experiments were performed in the presence of $0.2 \mathrm{mM} \mathrm{Bu}_{4} \mathrm{NPF}_{6}$ as the supporting electrolyte and the given potentials are referenced to the ferrocene/ ferrocenium couple, set as $0.00 \mathrm{~V}$. This scale can be related to saturated calomel electrode (SCE) conditions by adding $+0.46 \mathrm{~V}$ for $\mathrm{CH}_{2} \mathrm{Cl}_{2}$ and $+0.45 \mathrm{~V}$ for DMF solutions. ${ }^{[58]} \mathrm{NMR}$ : Bruker $\mathrm{AC}$ 250. IR: Elmer Paragon 1000 PC. UV/Vis: Omega 10 from Bruins Instruments or J\&M TIDAS diode array UV/Vis/NIR spectrometer equipped with a fiber-optic cable and operated with the SCAN 2017 and SPECTRALYS software packages. Electrochemistry: EG\&G potentiostat $273 \mathrm{~A}$, BAS glassy carbon working electrode $(\varnothing, 3 \mathrm{~mm}), \mathrm{Pt}$ wire as counter-electrode and $\mathrm{Ag}$ wire as pseudo-reference electrode, potential calibration by addition of ferrocene or decamethylferrocene as internal standard. EPR: Bruker ESP 300, HP frequency counter 5350 B, Bruker NMR gaussmeter ER $035 \mathrm{M}$, continuous flow cryostat ESR 900 from Oxford Instruments for low-temperature work

1-Ferrocenyl-1-phenylprop-2-yn-1-ol Trimethylsilyl Ether: $n \mathrm{BuLi}$ (4.6 $\mathrm{mL}$ of a $2.5 \mathrm{M}$ solution in $n$-hexane) was added to trimethylsilylacetylene $(1.6 \mathrm{~mL}, 1.11 \mathrm{~g}, 11.2 \mathrm{mmol})$ in degassed THF $(250 \mathrm{~mL})$. The clear, colorless solution was allowed to warm to room temperature, and benzoylferrocene $(2.32 \mathrm{~g}, 8 \mathrm{mmol})$ was added. The resulting solution was stirred for $20 \mathrm{~h}$, whereupon the color visibly brightened to orange. It was hydrolyzed with $5 \mathrm{~mL}$ of distilled water and the organic phase was taken to dryness. The brownish residue was taken up in dichloromethane, washed with several portions of a $5 \%$ solution of $\mathrm{Na}_{2} \mathrm{CO}_{3}$, and dried with $\mathrm{MgSO}_{4}$, and the solvent was removed in vacuo. The product was purified by column chromatography on neutral alumina with $n$-hexane/ $\mathrm{Et}_{2} \mathrm{O}(3: 1, \mathrm{v} / \mathrm{v})$ as the eluent. Slow evaporation of the solvents deposited orange crystals $(1.67 \mathrm{~g}, 4.3 \mathrm{mmol}, 54 \%)$.

1-Ferrocenyl-1-phenylprop-2-yn-1-ol: Finely ground $\mathrm{KOH}(1.68 \mathrm{~g}$, $30 \mathrm{mmol}$ ) was dissolved in $\mathrm{MeOH}$, and the silyl ether $(1.165 \mathrm{~g}$, $3 \mathrm{mmol}$ ) was added. The orange solution was kept under a gentle reflux for $18 \mathrm{~h}$ and the solvent was then distilled off. The residue was hydrolyzed in water and carefully acidified with dilute $\mathrm{HCl}$, and the product was extracted with $\mathrm{Et}_{2} \mathrm{O}$. The organic phase was washed with water and dried with $\mathrm{MgSO}_{4}$, and the solvent was removed in vacuo, which deposited the pure product as orange crystals $(0.81 \mathrm{~g}, 2.6 \mathrm{mmol}, 85 \%)$.

|Tp $\left(\mathrm{PPh}_{3}\right)_{2} \mathbf{R u}=\mathbf{C}=\mathbf{C}=\left.\mathrm{CPh}_{2}\right|^{+} \mathrm{SbF}_{6}{ }^{-}{ }^{-}$(2a): UV/Vis $\left(\mathrm{CH}_{3} \mathrm{CN}\right): \lambda_{\max }$ $(\varepsilon)=359$ (10500), 527 (16500), $901 \mathrm{~nm}\left(710 \mathrm{M}^{-1} \mathrm{~cm}^{-1}\right) ;\left(\mathrm{CH}_{2} \mathrm{Cl}_{2}\right)$ : $\lambda_{\max }(\varepsilon)=356(13000), 527(16000), 907 \mathrm{~nm}\left(660 \mathrm{M}^{-1} \mathrm{~cm}^{-1}\right)$. 
[Tp(dppf)Ru=C=C=CPh${ }^{+} \mathrm{SbF}_{6}{ }^{-}(\mathbf{2 b}): \mathrm{UV} / \mathrm{Vis}\left(\mathrm{CH}_{3} \mathrm{CN}\right): \lambda_{\max }$ $(\varepsilon)=346$ (11000), 520 (13000), $901 \mathrm{~nm}\left(350 \mathrm{~m}^{-1} \mathrm{~cm}^{-1}\right) ;\left(\mathrm{CH}_{2} \mathrm{Cl}_{2}\right)$ : $\lambda_{\text {max }}(\varepsilon)=356(16500), 522(19600), 902 \mathrm{~nm}\left(580 \mathrm{~m}^{-1} \mathrm{~cm}^{-1}\right)$.

$\left[\mathrm{Tp}\left(\mathrm{PPh}_{3}\right)_{2} \mathrm{Ru}=\mathrm{C}=\mathrm{C}=\mathrm{CFcPh}^{+} \mathrm{SbF}_{6}^{-} \quad\right.$ (3a): Compound 1a (250 mg, $\quad 0.286 \mathrm{mmol}), \quad$ 1-ferrocenyl-1-phenylprop-2-yn-1-ol (260 mg, $0.82 \mathrm{mmol}$ ), and $\mathrm{AgSbF}_{6}(190 \mathrm{mg}, 0.55 \mathrm{mmol})$ were mixed in THF $(10 \mathrm{~mL})$ in a Schlenk flask and stirred in the dark at ambient temperature for $40 \mathrm{~min}$, whereupon an intense purple color developed. THF was removed in vacuo and the solid residue was extracted with $\mathrm{CH}_{2} \mathrm{Cl}_{2}(15 \mathrm{~mL})$. Filtration through a fine frit covered with Celite $(10 \mathrm{~cm})$ and silica $(5 \mathrm{~cm})$, with use of small portions of $\mathrm{CH}_{2} \mathrm{Cl}_{2}$, removed the $\mathrm{AgCl}$. The solid residue obtained after the solvent had been pumped off, was subjected to column chromatography on silica (Merck 60) with $\mathrm{CH}_{2} \mathrm{Cl}_{2} / \mathrm{CH}_{3} \mathrm{CN}(10: 1, \mathrm{v} /$ $\mathrm{v})$ as the eluent. The first, orange band contained the excess propargylic alcohol, while the second, purple-black zone was slightly impure product. Further purification was performed by three successive reprecipitations from $\mathrm{CH}_{2} \mathrm{Cl}_{2}$ /hexanes. After drying in vacuo, spectroscopically pure product $(251 \mathrm{mg}, 0.183 \mathrm{mmol}, 64 \%)$ was obtained. Data for the major isomer: ${ }^{1} \mathrm{H}$ NMR $\left(\mathrm{CD}_{2} \mathrm{Cl}_{2}\right): \delta=4.28$ (s, $5 \mathrm{H}, \mathrm{C}_{5} \mathrm{H}_{5}$ ), 4.81, 5.05 (each t, ${ }^{3} J_{\mathrm{H}, \mathrm{H}}=2.0 \mathrm{~Hz}, 2 \mathrm{H}, \mathrm{Cp}_{\text {subst }}$ ), $5.58\left[\mathrm{t},{ }^{3} J_{\mathrm{H}, \mathrm{H}}=2.3 \mathrm{~Hz}, 1 \mathrm{H}, 4-\mathrm{H}(\mathrm{pz})\right], 5.69\left[\mathrm{~d},{ }^{3} J_{\mathrm{H}, \mathrm{H}}=2.3 \mathrm{~Hz}, 1\right.$ $\mathrm{H}, 3-\mathrm{H}(\mathrm{pz})], 5.72\left[\mathrm{t},{ }^{3} J_{\mathrm{H} . \mathrm{H}}=2.3 \mathrm{~Hz}, 2 \mathrm{H}, 4-\mathrm{H}(\mathrm{pz})\right], 6.31\left[\mathrm{~d},{ }^{3} J_{\mathrm{H}, \mathrm{H}}=\right.$ $2.3 \mathrm{~Hz}, 2 \mathrm{H}, 3-\mathrm{H}(\mathrm{pz})], 6.85-8.03$ (several $\mathrm{m}, 36 \mathrm{H}, 2 \mathrm{PPh}_{3}, \mathrm{Ph}$, $\mathrm{HB}), 7.66\left[\mathrm{~d},{ }^{3} J_{\mathrm{H}, \mathrm{H}}=2.3 \mathrm{~Hz}, 2 \mathrm{H}, 5-\mathrm{H}(\mathrm{pz})\right], 7.85\left[\mathrm{~d},{ }^{3} J_{\mathrm{H}, \mathrm{H}}=\right.$ $2.3 \mathrm{~Hz}, 1 \mathrm{H}, 5-\mathrm{H}(\mathrm{pz})] \mathrm{ppm} .{ }^{13} \mathrm{C}\left\{{ }^{1} \mathrm{H}\right\}$ NMR $\left(62.9 \mathrm{MHz}, \mathrm{CD}_{2} \mathrm{Cl}_{2}\right)$ : $\delta=71.6\left(\mathrm{C}_{i p s o}, \mathrm{Fc}\right), 73.2\left(\mathrm{C}_{5} \mathrm{H}_{5}\right), 74.5,78.3\left(\mathrm{C}-2-5, \mathrm{Cp}_{\text {sub }}\right)$, 105.7, 106.5 [br., C-4(pz)], 125.5-134.5 (several m, $2 \mathrm{PPh}_{3}, \mathrm{Ph}$ ), 136.5, 137.0 (br., C-5(pz)], $144.9\left(\mathrm{C}_{\text {ipso }} \mathrm{Ph}\right), 145.3,147.0(\mathrm{C}-3(\mathrm{pz})], 168.2$ $\left(\mathrm{t},{ }^{4} J_{\mathrm{P}, \mathrm{C}}=1.6 \mathrm{~Hz}, \mathrm{C}-\gamma\right), 184.3\left(\mathrm{t},{ }^{3} J_{\mathrm{P}, \mathrm{C}}=1.5 \mathrm{~Hz}, \mathrm{C}-\beta\right), 287.0[\mathrm{t}$, $\left.J_{\mathrm{PC}}=18.2 \mathrm{~Hz}, \mathrm{C}-\alpha\right] \mathrm{ppm} .{ }^{31} \mathrm{P}\left\{{ }^{1} \mathrm{H}\right\}$ NMR $\left(101.3 \mathrm{MHz}, \mathrm{CD}_{2} \mathrm{Cl}_{2}\right)$ : $\delta=40.8$ (s) ppm. IR (KBr): $\tilde{v}=1946$ (vs, $\mathrm{C}=\mathrm{C}=\mathrm{C}$ ), 1458 (s, Fc), $1436(\mathrm{~s}, \mathrm{Ph}), 1382(\mathrm{~m}, \mathrm{Ph}), 1309(\mathrm{~m}, \mathrm{Ph}), 1049(\mathrm{~m}, \mathrm{Ph}), 749(\mathrm{~m}$,
$\mathrm{Ph}), 699(\mathrm{~s}, \mathrm{Ph}), 658 \mathrm{~cm}^{-1}\left(\mathrm{SbF}_{6}\right)$. UV/Vis $\left(\mathrm{CH}_{3} \mathrm{CN}\right): \lambda_{\max }(\varepsilon)=$ 355 (3600), 534 (5200), $719\left(2650 \mathrm{M}^{-1} \mathrm{~cm}^{-1}\right) ; 825 \mathrm{~nm}(\mathrm{sh})$; $\left(\mathrm{CH}_{2} \mathrm{Cl}_{2}\right): \lambda_{\max }(\varepsilon)=356(8000), 538(11500), 724 \mathrm{~nm}\left(5700 \mathrm{M}^{-1}\right.$ $\left.\mathrm{cm}^{-1}\right) . \mathrm{C}_{64} \mathrm{H}_{54} \mathrm{BF}_{6} \mathrm{FeN}_{6} \mathrm{P}_{2} \mathrm{RuSb}$ (1372.59): calcd. C 56.00, H 3.97, $\mathrm{N}$ 6.12; found C 55.78, H 4.20, N 5.61.

$\left[\mathrm{Tp}(\mathrm{dppf}) \mathrm{Ru}=\mathrm{C}=\mathrm{C}=\mathrm{CF}_{\mathrm{chh}}{ }^{+} \mathrm{SbF}_{6}{ }^{-}(3 \mathrm{~b})\right.$ : This compound was prepared analogously to the method described for the synthesis and purification of compound 3a. The product $(289 \mathrm{mg}, 74.7 \%)$ was obtained from 1 b $\quad(250 \mathrm{mg}, \quad 0.276 \mathrm{mmol}), \quad$-ferrocenyl-1phenylprop-2-yn-1-ol $(0.26 \mathrm{~g}, 0.82 \mathrm{mmol})$, and $\mathrm{AgSbF}_{6}(190 \mathrm{mg}$, $0.55 \mathrm{mmol})$. ' $\mathrm{H} \mathrm{NMR}\left(\mathrm{CD}_{2} \mathrm{Cl}_{2}\right): \delta=4.22\left(\mathrm{~s}, 5 \mathrm{H}, \mathrm{C}_{5} \mathrm{H}_{5}\right), 4.67,4.76$ [each br., $4 \mathrm{H}, 2,3-\mathrm{H}(\mathrm{dppf})$ ], $5.05,5.12\left(\right.$ each t, ${ }^{3} J_{\mathrm{H} . \mathrm{H}}=2.1 \mathrm{~Hz}, 2$ $\left.\mathrm{H}, \mathrm{Cp}_{\text {subst }}\right), 5.39\left[\mathrm{t},{ }^{3} J_{\mathrm{H}, \mathrm{H}}=1.9 \mathrm{~Hz}, 2 \mathrm{H}, 4-\mathrm{H}(\mathrm{pz})\right], 5.93\left[\mathrm{t},{ }^{3} J_{\mathrm{H}, \mathrm{H}}=\right.$ $2.2 \mathrm{~Hz}, 1 \mathrm{H}, 4-\mathrm{H}(\mathrm{pz})], 6.33\left[\mathrm{~d},{ }^{3} J_{\mathrm{H} . \mathrm{H}}=2.2 \mathrm{~Hz}, 1 \mathrm{H}, 3-\mathrm{H}(\mathrm{pz})\right], 6.39$ $\left[\mathrm{d},{ }^{3} J_{\mathrm{H}, \mathrm{H}}=1.9 \mathrm{~Hz}, 2 \mathrm{H}, 3-\mathrm{H}(\mathrm{pz})\right], 6.42-8.20$ (several m, $26 \mathrm{H}, 2$ $\left.\mathrm{PPh}_{2}, \mathrm{Ph}, \mathrm{HB}\right), 7.64\left[\mathrm{~d},{ }^{3} J_{\mathrm{H}, \mathrm{H}}=2.2 \mathrm{~Hz}, 1 \mathrm{H}, 5-\mathrm{H}(\mathrm{pz})\right], 7.81[\mathrm{~d}$, $\left.{ }^{3} J_{\mathrm{H}, \mathrm{H}}=1.9 \mathrm{~Hz}, 2 \mathrm{H}, 5-\mathrm{H}(\mathrm{pz})\right] \mathrm{ppm} .{ }^{13} \mathrm{C}\left\{{ }^{1} \mathrm{H}\right\} \mathrm{NMR}(62.9 \mathrm{MHz}$, $\left.\mathrm{CD}_{2} \mathrm{Cl}_{2}\right): \delta=70.6\left(\mathrm{C}_{i p s o}, \mathrm{Fc}\right), 73.3\left[\mathrm{t},{ }^{2} J_{\mathrm{P}, \mathrm{C}}=3.6 \mathrm{~Hz}, \mathrm{C}-2 / 5(\mathrm{dppf})\right]$, $73.59\left[\mathrm{C}_{i p s o}(\mathrm{dppf})\right], 73.63\left(\mathrm{C}_{5} \mathrm{H}_{5}\right), 73.9\left(\mathrm{Cp}_{\text {sub }}\right), 74.6\left[\mathrm{t},{ }^{3} J_{\mathrm{P}, \mathrm{C}}=\right.$ $2.9 \mathrm{~Hz}, \quad \mathrm{C}-3 / 4(\mathrm{dppf}), \quad 79.0 \quad\left(\mathrm{Cp}_{\text {sub }}\right), \quad 106.0, \quad 106.5 \quad$ [C-4(pz)], 128.0-133.5 (several m, $2 \mathrm{PPh}_{2}, \mathrm{Ph}$ ), 135.4, 137.3 [br., C-5(pz)], $144.0\left(\mathrm{t},{ }^{5} J_{\mathrm{P}, \mathrm{C}}=0.7 \mathrm{~Hz}, \mathrm{C}_{i p s o}, \mathrm{Ph}\right), 144.8\left[\mathrm{t},{ }^{3} J_{\mathrm{P}, \mathrm{C}}=1.1 \mathrm{~Hz}, \mathrm{C}-\right.$ $3(\mathrm{pz})], 147.3\left(\mathrm{t},{ }^{3} J_{\mathrm{P}, \mathrm{C}}=1.5 \mathrm{~Hz}\right), 167.9\left(\mathrm{t},{ }^{4} J_{\mathrm{P}, \mathrm{C}}=1.5 \mathrm{~Hz}, \mathrm{C}-\gamma\right)$, 180.6 (br., C- $\beta$ ), 283.7 [t, $\left.J_{\mathrm{PC}}=18.2 \mathrm{~Hz}, \mathrm{C}-\boldsymbol{\alpha}\right] \mathrm{ppm} .{ }^{31} \mathrm{P}\left\{{ }^{1} \mathrm{H}\right\} \mathrm{NMR}$ $\left(101.3 \mathrm{MHz}, \mathrm{CD}_{2} \mathrm{Cl}_{2}\right): \delta=29.9(\mathrm{~s}) \mathrm{ppm}$. IR $(\mathrm{KBr}): \tilde{v}=1941$ (vs, $\mathrm{C}=\mathrm{C}=\mathrm{C}), 1457(\mathrm{~s}, \mathrm{Fc}), 1435(\mathrm{~s}, \mathrm{Ph}), 1395(\mathrm{~m}, \mathrm{Ph}), 1382(\mathrm{~m}, \mathrm{Ph})$, $1309(\mathrm{~m}, \mathrm{Ph}), 1049(\mathrm{~m}, \mathrm{Ph}), 749(\mathrm{~m}, \mathrm{Ph}), 697(\mathrm{~s}, \mathrm{Ph}), 658\left(\mathrm{SbF}_{6}\right)$ $\mathrm{cm}^{-1}$. UV/Vis $\left(\mathrm{CH}_{3} \mathrm{CN}\right): \lambda_{\max }(\varepsilon)=348(14000), 534$ (15500), 709 (10000), $1030 \mathrm{~nm}\left(800 \mathrm{~m}^{-1} \mathrm{~cm}^{-1}\right) ;\left(\mathrm{CH}_{2} \mathrm{Cl}_{2}\right): \lambda_{\max }(\varepsilon)=350$ (16500), 540 (19500), 712 (13000), $1030 \mathrm{~nm}\left(2000 \mathrm{M}^{-1} \mathrm{~cm}^{-1}\right)$. $\mathrm{C}_{62} \mathrm{H}_{52} \mathrm{BF}_{6} \mathrm{Fe}_{2} \mathrm{~N}_{6} \mathrm{P}_{2} \mathrm{RuSb}$ (1402.40): calcd. C 53.10, H 3.73, N 5.99; found $\mathrm{C} 52.32$, H 3.85, N 5.54 .

Table 7. Crystallographic data for $[\mathrm{TpRu}(\mathrm{dppf}) \mathrm{Cl}] \cdot 2 \mathrm{CHCl}_{3}$ and $\left[\mathrm{Tp}(\mathrm{dppf}) \mathrm{RuC}_{3} \mathrm{Ph}_{2}\right]^{+} \mathrm{SbF}_{6}{ }^{-}$

\begin{tabular}{|c|c|c|}
\hline & {$[\mathrm{TpRu}(\mathrm{dppf}) \mathrm{Cl}] \cdot 2 \mathrm{CHCl}_{3}$} & {$\left[\mathrm{Tp}(\mathrm{dppf}) \mathrm{RuC}_{3} \mathrm{Ph}_{2}\right]^{+} \mathrm{SbF}_{6}^{-}$} \\
\hline Empirical formula & $\mathrm{C}_{45} \mathrm{H}_{40} \mathrm{BCl}_{7} \mathrm{FeN}_{6} \mathrm{P}_{2} \mathrm{Ru}$ & $\mathrm{C}_{58} \mathrm{H}_{48} \mathrm{BF}_{6} \mathrm{FeN}_{6} \mathrm{P}_{2} \mathrm{RuSb}$ \\
\hline Formula mass & 1142.65 & 1294.44 \\
\hline Temperature [K] & $173(2)$ & $293(2)$ \\
\hline Wavelength $[\AA]$ & 0.71073 & 0.71073 \\
\hline Crystal system & monoclinic & orthorhombic \\
\hline Space group & $P 2_{1} / n$ & Pbca \\
\hline 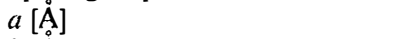 & $13.977(3)$ & $21.9546(14)$ \\
\hline$b[\AA]$ & $17.287(4)$ & $27.959(3)$ \\
\hline$c[\AA]$ & $19.645(4)$ & $22.152(2)$ \\
\hline$\beta\left[{ }^{\circ}\right]$ & $91.85(3)$ & 90 \\
\hline$V\left[\AA^{3}\right]$ & $4744.1(16)$ & $13597(2)$ \\
\hline $\mathrm{Z}$ & 4 & 8 \\
\hline Density (calculated) $\left[\mathrm{Mg} / \mathrm{m}^{3}\right]$ & 1.600 & 1.265 \\
\hline Absorption coefficient $\left[\mathrm{mm}^{-1}\right]$ & 1.127 & 0.924 \\
\hline$F(000)$ & 2304 & 5184 \\
\hline Crystal size $[\mathrm{mm}]$ & $0.3 \times 0.25 \times 0.15$ & $0.25 \times 0.07 \times 0.07$ \\
\hline$\theta$ range for data collection $\left[{ }^{\circ}\right]$ & 1.57 to 29.03 & 1.96 to 19.04 \\
\hline Index ranges for data collection & $0 \leq h \leq 19,-14 \leq k \leq 23,-22 \leq l \leq 26$ & $-18 \leq h \leq 20,-25 \leq k \leq 25,-18 \leq l \leq 19$ \\
\hline No. of reflections measured & 12760 & 15729 \\
\hline No. of independent reflections & $8069[\mathrm{R}(\mathrm{int})=0.0526]$ & 4616 \\
\hline Refinement method & full-matrix least-squares on $F^{2}$ & full-matrix least-squares on $F^{2}$ \\
\hline Data/restraints/parameters & $12373 / 0 / 573$ & $4616 / 0 / 360$ \\
\hline Goodness-of-fit on $F^{2}$ & 1.288 & 1.522 \\
\hline Final $R$ indices $[I>4 \sigma(I)]$ & $R 1=0.0757, w R 2=0.1829$ & $R \mathrm{l}=0.156, w R 2=0.4112$ \\
\hline$R$ indices (all data) & $R 1=0.1269, w R 2=0.2218$ & $R 1=0.2473, w R 2=0.4528$ \\
\hline Largest diff. peak/hole $\left[\mathrm{e} \cdot \AA^{-3}\right]$ & $2.10 /-2.34$ & $1.648 /-1.863$ \\
\hline
\end{tabular}


$\mathrm{X}$-ray Crystallography: Crystals of complex $\mathbf{1 b}$ were grown by slow concentration of a saturated solution in $\mathrm{CHCl}_{3}$ while those of $\mathbf{2 b}$ were obtained by cooling a solution in a $\mathrm{THF} / \mathrm{Et}_{2} \mathrm{O}$ mixture to -15 ${ }^{\circ} \mathrm{C}$. Experimental details regarding the $\mathrm{X}$-ray structure solutions are provided in Table 7. The structures were solved by direct methods, least-squares refinement, and Fourier techniques. Structure solution and refinement were performed with SHELXTL. ${ }^{[59]}$ CCDC-192092 (2b) and -192093 (1b) contain the supplementary crystallographic data for this paper. These data can be obtained free of charge at www.ccdc.cam.ac.uk/conts/retrieving.html [or from the Cambridge Crystallographic Data Centre, 12 Union Road, Cambridge CB2 1EZ, UK; Fax: (internat.) + 44-1223/336033; E-mail: deposit@ccdc.cam.ac.uk].

\section{Acknowledgments}

We are grateful to the Volkswagenstiftung for financial support within their program on intra- and intermolecular electron transfer. We also wish to acknowledge Johnson \& Matthey Company for a generous loan of $\mathrm{RuCl}_{3}$ hydrate.

[1] R. F. Winter, Eur: J. Inorg. Chem. 1999, 2121-2126.

[2] S. Hartmann, R. F. Winter, T. Scheiring, M. Wanner, J. Organomet. Chem. 2001, 637-639, 240.

[3] R. F. Winter, Organometallics 1997, 16, 4248-4250.

[4] R. F. Winter, K.-W. Klinkhammer, S. Záliš, Organometallics 2001, 20, 1317-1333.

[5] M. I. Bruce, P. Hinterding, P. J. Low, B. W. Skelton, A. H. White, Chem. Commun. 1996, 1009-1010.

${ }^{[6]}$ M. I. Bruce, P. Hinterding, P. J. Low, B. W. Skelton, A. H. White, J. Chem. Soc., Dalton Trans. 1998, 467-473.

[7] V. Guillaume, P. Thominot, F. Coat, A. Mari, C. Lapinte, J. Organomet. Chem. 1998, 565, 75-80.

[8] M. I. Bruce, Chem. Rev. 1998, 98, 2797-2858.

[9] V. Cadierno, M. P. Gamasa, J. Gimeno, M. González-Cueva, E. Lastra, J. Borge, S. García-Granda, E. Pérez-Carreño, Organometallics 1996, 15, 2137-2147.

${ }^{[10]}$ M. A. Esteruelas, A. V. Gómez, A. M. López, J. Modrego, E. Oñate, Organometallics 1997, 16, 5826-5835.

${ }^{[11]}$ M. Baya, P. Crochet, M. A. Esteruelas, E. Gutiérrez-Puebla, A. M. López, J. Modrego, E. Oñate, N. Vela, Organometallics 2000, 19, 2585-2596.

${ }^{[12]}$ R. F. Winter, Chem. Commun. 1998, 2209-2210.

${ }^{[13]}$ B. Buriez, I. D. Burns, A. F. Hill, A. J. P. White, D. J. Williams, J. D. E. T. Wilton-Ely, Organometallics 1999, 18, 1504-1516.

${ }^{[14]}$ B. Buriez, D. J. Cook, K. J. Harlow, A. F. Hill, T. Welton, A. J. P. White, D. J. Williams, J. D. E. T. Wilton-Ely, J. Organomet. Chem. 1999, 264-267.

${ }^{[15]}$ K. J. Harlow, A. F. Hill, T. Welton, J. Chem. Soc., Dalton Trans. 1999, 1911-1912.

${ }^{[16]}$ M. A. J. Tenorio, M. J. Tenorio, M. C. Puerta, P. Valerga, Organometallic 1997, 16, 5528-5535.

${ }^{[17]}$ N. W. Alcock, I. D. Burns, K. S. Claire, A. F. Hill, Inorg. Chem. 1992, 31, 2906-2908.

${ }^{[18]}$ C. Slugovc, V. N. Sapunov, P. Wiede, K. Mereiter, R. Schmid, K. Kirchner, J. Chem. Soc., Dalton Trans. 1997, 4209-4216.

${ }^{[19]}$ S. Pavlik, C. Gemel, C. Slugovc, K. Mereiter, R. Schmid, K. Kirchner, J. Organomet. Chem. 2001, 617-618, 301-310.

${ }^{[20]}$ M. Tamm, T. Jentzsch, W. Werncke, Organometallics 1997, $16,1418-1422$.

${ }^{[21]}$ M. Tamm, A. Grzegorzewski, I. Brïdgam, H. Hartl, J. Chem. Soc., Dalton Trans. 1998, 3523-3528.

${ }^{[22]}$ A. Z. Kreindlin, F. M. Dolgushin, A. I. Yanovsky, Z. A. Kerzina, P. V. Petrovskii, M. I. Rybinskaya, J. Organomet. Chem. 2000, 616, 106-111.
[23] D. Pilette, K. Ouzzine, H. Le Bozec, P. H. Dixneuf, C. E. F. Rickard, W. R. Roper, Organometallics 1992, 11, 809-817.

${ }^{[24]}$ D. Touchard, N. Pirio, P. H. Dixneuf, Organomerallics 1995, 14, 4920-4928.

${ }^{[25]}$ N. M. Kostic, R. F. Fenske, Organometallics 1982, 1, 974-982.

[26] G. Consiglio, F. Bangerter, C. Darpin, Organometallics 1984, $3,1448-1450$

${ }^{[27]}$ G. Consiglio, F. Morandini, Inorg. Chim. Acta 1987, 127, 79-85.

[28] M. P. Gamasa, J. Gimeno, E. Lastra, B. M. Martín, A. Anillo, A. Tiripicchio, Organometallics 1992, 11, 1373-1381.

${ }^{[29]}$ K. Urtel, A. Frick, G. Huttner, L. Zsolnai, P. Kircher, P. Rutsch, E. Kaifer, A. Jacobi, Eur. J. Inorg. Chem. 2000, 33-50.

${ }^{[30]}$ D. Unseld, V. V. Krivykh, K. Heinze, F. Wild, G. Artus, H. Schmalle, H. Berke, Organometallics 1999, 18, 1525-1541.

${ }^{[31]}$ R. L. Beddoes, C. Bitchon, R. W. Grime, A. Ricalton, M. W. Whiteley, J. Chem. Soc., Dalton Trans. 1995, 2873-2883.

${ }^{[32]}$ A. Wong, J. A. Gladysz, J. Am. Chem. Soc. 1982, 104, 4948-4950.

${ }^{[33]}$ B. E. R. Schilling, R. Hoffmann, D. L. Lichtenberger, J. Am. Chem. Soc. 1979, 101, 585.

${ }^{[34]}$ H. Goetz, F. Nerdel, K.-H. Wiechel, Justus Liebigs Ann. Chem. 1963, 665, 1-14.

${ }^{[35]}$ S. Rigaut, O. Maury, D. Touchard, P. H. Dixneuf, Chem. Commun. 2001, 373-374.

[36] R. S. Nicholson, I. Shain, Anal. Chem. 1964, 36, 706-723.

[37] [37a] N. Re, A. Sgamellotti, C. Floriani, Organometallics 2000, 19, 1115-1122. ${ }^{[376]}$ A. Marrone, N. Re, Organometallics 2002, $21,3562-3571$.

${ }^{[38]}$ M. I. Bruce, Chem. Rev. 1991, 91, 107-257.

${ }^{[39]}$ M. I. Bruce, M. G. Humphrey, G. A. Koutsantonis, M. J. Liddell, J. Organomet. Chem. 1987, 326, 247-256.

${ }^{[40]}$ M. I. Bruce, G. A. Koutsantonis, M. J. Liddell, B. K. Nicholson, J. Organomet. Chem. 1987, 320, 217-227.

${ }^{[41]}$ M. I. Bruce, M. G. Humphrey, M. J. Liddell, J. Organomet. Chem. 1987, 321, 91-102.

${ }^{[42]}$ M. I. Bruce, M. G. Humphrey, Aust. J. Chem. 1989, 42, 1067-1075.

${ }^{[43]}$ K. J. Harlow, A. F. Hill, J. D. E. T. Wilton-Ely, J. Chem. Soc., Dalton Trans. 1999, 285-291.

${ }^{[44]}$ R. M. Badger, J. Chem. Phys. 1937, 5, 178.

${ }^{[45]}$ R. Denis, L. Toupet, F. Paul, C. Lapinte, Organometallics 2000, $19,4240-4251$.

${ }^{[46]}$ F. Paul, J.-Y. Mevellec, C. Lapinte, J. Chem. Soc., Dalton Trans. 2002, 1783-1790.

${ }^{[47]}$ I. S. Zavarine, C. P. Kubiak, T. Yamaguchi, K.-i. Ota, T. Matsui, T. Ito, Inorg. Chem. 2000, 39, 2696-2698.

${ }^{[48]}$ R. F. Winter, S. Hartmann, S. Zalis, K.-W. Klinkhammer, to be submitted to J. Chem. Soc., Dalton Trans.

${ }^{[49]}$ V. Cadierno, M. P. Gamasa, J. Gimeno, Eur. J. Inorg. Chem. 2001, 571-591.

[50] A. Bromberg, D. Meisel, J. Phys. Chem. 1985, 89, 2507-2513.

[51] J. L. Faria, S. Steenken, J. Phys. Chem. 1993, 97, 1924-1930.

${ }^{\left[{ }^{52]} \mathrm{M}\right.}$. B. Jones, V. M. Maloney, M. S. Platz, J. Am. Chem. Soc. $1992,114,2163-2169$.

${ }^{[53]}$ D. Weir, J. Phys. Chem. 1990, 94, 5870-5875.

${ }^{[54]}$ M. Akita, K. Ohta, Y. Takahashi, S. Hikichi, Y. Moro-Oka, Organometallics 1997, 16, 4121-2128.

${ }^{[55]}$ T. J. Bunker, A. R. Cowley, D. O'Hare, Organometallics 2002, $21,3123-3138$.

[56] J. Tirouflet, R. Dabard, E. Laviron, Bull. Chem. Soc. Fr. 1963,1655 .

[57] G. W. Gokel, I. K. Ugi, J. Chem. Educ. 1972, 49, 294

${ }^{[58]}$ N. G. Connelly, W. E. Geiger, Chem. Rev. 1996, 96, 877-910.

${ }^{[59]}$ G. M. Sheldrick, Institut für Anorganische Chemie der Universität, Tammanstraße 4: Göttingen, 1997. 